\title{
REFLEXIONES PRÁCTICAS CON 842 DÍAS EN HACIENDA
}

\author{
Rodrigo Valdés \\ Escuela de Gobierno UC
}

\begin{abstract}
Resumen: Durante el segundo gobierno de la Presidenta Bachelet, Chile enfrentó simultáneamente desafíos fiscales significativos, el diseño e implementación de varias reformas estructurales y la desaceleración económica más prolongada en décadas. Bajo la mirada de quien fue el segundo ministro de Hacienda de esta administración, se revisan algunos de estos temas y se analizan aspectos técnicos y políticos, así como la racionalidad detrás de algunas decisiones económicas. También se evalúan preliminarmente algunos resultados y se discuten temas de política pública específicos que probablemente continuarán en la agenda los próximos años.
\end{abstract}

Palabras clave: Michelle Bachelet, Ministerio de Hacienda, reforma tributaria, reforma laboral, reforma educacional, gratuidad universitaria, desempeño económico chileno.

Rodrigo VALdÉs. Economista de la Universidad de Chile y PhD por el MIT. Ministro de Hacienda de Chile entre abril de 2015 y agosto de 2017. Profesor asociado Pontificia Universidad Católica. Email: rodrigo.valdes@uc.cl.

El autor agradece los comentarios de Marcela Gómez, Sergio Granados, Osvaldo Larrañaga, Enrique Paris, Valentina Quiroga y Rodrigo Vergara. Advierte, además, que lo que dice aquí es de su exclusiva responsabilidad. 


\title{
SOME PRACTICAL REFLECTIONS FROM 842 DAYS IN THE MINISTRY OF FINANCE
}

\begin{abstract}
During Michelle Bachelet's second presidency, Chile had simultaneously to face up to significant fiscal challenges, design and implement a number of structural reforms and cope with the longest economic slowdown in decades. In this article, that administration's second finance minister reviews some of these issues and analyses the technical and political aspects and underlying rationale of certain economic decisions. It also offers a preliminary assessment of some of their results and discusses specific public policy concerns that will probably remain on the agenda over the coming years.
\end{abstract}

Keywords: Michelle Bachelet, Ministry of Finance, tax reform, employment reform, educational reform, free university tuition, Chilean economic performance.

\section{INTRODUCCIÓN}

$S$ er ministro de Hacienda entrega una experiencia y perspectiva únicas en la discusión de las políticas públicas en Chile. Por la estructura del gobierno, ese ministerio encabeza el equipo económico y se involucra en múltiples temas, sea directamente, porque comprenden uso de recursos, o indirectamente, porque se trata de políticas públicas que afectan la economía o la organización del Estado. El ministro también participa en el Comité Político, lo que entrega una panorámica distinta y complementaria. El ejercicio del cargo brinda, simultáneamente, el conocimiento de temas específicos y una perspectiva global.

A partir de esa experiencia, esta nota revisa y discute una serie de temas que estuvieron en la agenda en los últimos años. Específicamente, se centra en tres: (i) el problema fiscal; (ii) tres de las reformas emblemáticas: tributaria, laboral y educacional, y (iii) la disminución del crecimiento. En cada caso, se describen algunos de los principales hitos y decisiones; cuando es posible, se presenta una breve evaluación preliminar, y se discuten algunas ideas y reflexiones que pueden ser útiles en discusiones futuras en estos ámbitos.

Para otra oportunidad queda reflexionar sobre los aspectos de organización política (incluidos la descentralización y el sistema político, entre otros), la Agenda de Probidad y Transparencia - probablemente, uno de los legados principales del segundo gobierno de Michelle Ba- 
chelet-, la reforma de pensiones (que sólo alcanzamos a presentar en el Congreso) y varios cambios más específicos, pero relevantes, que se gestionaron desde Hacienda, especialmente respecto de regulaciones en el ámbito financiero.

\section{LATENSIÓN FISCAL}

A partir de 2015, Chile enfrentó el problema fiscal de mayor complejidad registrado desde la recuperación de la democracia. No era una situación extrema como las que han sufrido otras economías o nuestro propio país postcrisis de 1982, cuando los mercados financieros globales o el Fondo Monetario Internacional terminan imponiendo restricciones al gasto público. Pero pudimos haber caído en una espiral de problemas si no hubiéramos reconocido a tiempo que había que ajustar los planes de gasto, lo que hicimos con una estrategia responsable y creíble. No se debe olvidar que los mercados abandonan a los países sin aviso previo y violentamente.

\subsection{Gradualidad como compromiso}

A pesar de la mayor recaudación que teóricamente produciría la reforma tributaria aprobada por el gobierno y la oposición en 2014 (cerca de 3 por ciento del PIB hacia 2018), en 2015 comenzó una tensión fiscal creciente. Se combinó, por un lado, un programa de gobierno que implicaba gastos fiscales permanentes significativos, que en algunos casos resultaron ser mayores que los previstos inicialmente. ${ }^{1}$ Por otro lado, el país tenía una merma potencialmente elevada en los ingresos fiscales, tanto por la disminución de la tasa de crecimiento del PIB y su

${ }^{1}$ Algunos costos superaron lo inicialmente estimado, como la gratuidad universitaria universal. En otros casos, los costos aumentaron por decisiones de política, como en el caso del fin del copago en colegios subvencionados (que se legisló con una trayectoria más rápida) y la carrera docente (que fue más allá del sistema estatal). De acuerdo al "Informe de Finanzas Públicas. Proyecto de Ley de Presupuestos del Sector Público para el año 2018”, el gasto incremental en régimen de las reformas en educación sería de cerca de 3,2 por ciento del PIB, mientras que el programa de gobierno lo cifró entre 1,5 y dos por ciento del PIB. También existían ítems en el programa que hablaban genéricamente de estudios y mejoramientos, y no fueron inicialmente incluidos en el plan de gastos; por ejemplo, las reformas al Servicio Nacional de Menores (Sename). 
efecto en los ingresos tributarios, como por el menor precio del cobre. Además, en ese tiempo existía enorme incertidumbre respecto de cómo evolucionarían estos ingresos.

Gracias a la conducción fiscal desde 1990, la deuda pública en Chile era muy baja a comienzos del gobierno: a fines de 2014 era 14,9 por ciento del PIB y la deuda neta era negativa: $-4,3$ por ciento del PIB. La elevada clasificación de riesgo, el hecho de tener fondos soberanos significativos, el bajo nivel de las tasas de interés locales y externas y el enorme pool de ahorro que manejan los inversionistas institucionales implicaban que se podía financiar estos déficits por un tiempo considerable y probablemente a tasas de interés reducidas.

En este escenario, desde el punto de vista macroeconómico no era evidente cuánto se debía ajustar y cuánto déficit se debía financiar. Si el shock de ingresos era de corta duración, se podía acomodar con un mayor déficit. Si el shock era duradero, había que ajustar más. En principio, esto es justamente lo que hace la regla estructural, aunque era difícil saber con certeza el valor de los parámetros estructurales, como por ejemplo el precio del cobre de largo plazo.

Además, en la discusión económica global se había revaluado el efecto y el rol de la política fiscal en el ciclo económico. La discusión en el Fondo Monetario Internacional (FMI), unos pocos años antes, fue justamente que los ajustes fiscales postcrisis de 2009 tuvieron efectos contractivos mayores que los esperados. En varios países fue difícil que la política monetaria acompañara el ajuste, ya sea por restricciones de credibilidad o, simplemente, por un agotamiento de las herramientas monetarias.

Esto llevaba a un ángulo keynesiano puro y duro: ¿por qué no expandir el gasto en serio si la economía está creciendo bajo su potencial y existe acceso barato al financiamiento? La reacción fiscal en 2009, cuando el gasto aumentó en 16,5 por ciento, era el mejor ejemplo. Sin embargo, lo que estábamos enfrentando ahora podía ser un shock duradero, incluso estructural, no algo transitorio. El caso de España durante la crisis europea, que reaccionó con una fuerte expansión fiscal a un problema estructural, mostró el peligro de usar el remedio en condiciones equivocadas.

También había consideraciones políticas. Primero, modificar el programa de gobierno suponía costos importantes en credibilidad y po- 
tencialmente en adhesión (por cierto, se exceptúa el cambio del objetivo de volver al balance estructural en 2018). ${ }^{2}$ Segundo, la discusión pública sobre política fiscal durante este período seguía su habitual confusión entre tamaño del Estado y consideraciones macroeconómicas de corto plazo. La derecha empujaba por ajustar el gasto, mezclando su aspiración a mantener un Estado pequeño con la discusión macroeconómica, y la izquierda hacía justamente lo contrario.

Considerando todo lo anterior, a partir de mediados de 2015 la política fiscal se orientó a ajustar gradualmente el déficit estructural. Hubo lo que se denomina "amplio espacio fiscal", pero la prudencia llamaba a ocuparlo con cuidado. Para esto era imprescindible un cambio de foco hacia la responsabilidad y la austeridad. También sería necesario un cambio en la meta de la regla fiscal y establecer nuevos objetivos cuantitativos.

\subsection{Implementación práctica}

Las posibilidades respecto de cuánto gastar cambiaron significativamente en los primeros meses de 2015. Con los parámetros macroeconómicos del programa de gobierno, el gasto fiscal podía crecer aproximadamente 6,5 por ciento por año en el periodo 2014-18 (suponiendo que los ingresos de la reforma tributaria se gastaban gradualmente en cinco años). Esto consideraba un crecimiento de tendencia de la economía de 4,5 por ciento más los 2 puntos del PIB que se podrían gastar de la reforma tributaria (ya que, según el programa, un punto se ahorraría). Pero aparecieron dos problemas y un gran riesgo. Primero, el 4,5 por ciento de crecimiento de tendencia se estaba transformando en 3,5 por ciento o menos (dos años después sería incluso menor a 3 por ciento). Y segundo, el presupuesto del 2015 se diseñó con un aumento de gasto de casi 10 por ciento, lo que usaba el espacio de los años siguientes. Ambas realidades implicaban que, para volver a un resultado estructural cero, en los siguientes tres años el crecimiento máximo del gasto debería estar en torno a 4 por ciento promedio. Y esto sin considerar

2 También existía la duda acerca de cómo compatibilizar objetivos que podrían aparecer como contrapuestos en la conducción económica, como mantener el orden fiscal e influir en la agenda microeconómica y de incentivos. En retrospectiva, no es evidente que exista un trade-off entre ambos. 
que el precio del cobre podía seguir disminuyendo, como efectivamente ocurrió. $^{3}$

Esta situación fiscal hizo que el espacio para nuevos anuncios en la Cuenta Pública Presidencial del 21 de mayo se redujera, al tiempo que se remarcó la importancia de la responsabilidad y de que enfrentábamos una situación más complicada que la esperada. Se incluyeron pocos gastos nuevos y se precisó que la gratuidad comenzaría para el 60 por ciento más vulnerable en universidades del Consejo de Rectores de las Universidades Chilenas (Cruch) y en centros de formación técnica (CFT) e institutos profesionales (IP) acreditados y sin fines de lucro, además de un avance acotado del programa de capacitación +Capaz, que era parte del programa de gobierno. La atención a los problemas en el financiamiento de la política y otros casos que involucraban fallas éticas y de regulación también ayudaron a un discurso sobrio.

Con el correr de las semanas y meses, la brecha entre lo que se podía financiar y lo que se planeaba gastar sólo creció. ${ }^{4}$ Se veía cada vez más difícil volver al balance estructural en 2018. El precio efectivo del cobre únicamente disminuía y era cada vez más probable que el llamado precio de referencia, insumo central para el balance estructural, disminuyera significativamente por primera vez desde que se implementó la regla fiscal en 2001. Un cálculo simple sugería que podía ser necesario congelar el gasto por dos o tres años, algo políticamente inviable y económicamente insensato. De hecho, la tasa de interés de los bonos del gobierno sólo disminuía y llegaba a mínimos históricos, ratificando que había bastante espacio fiscal. El Banco Central, por su parte, estaba cada vez más incómodo con la inflación que seguía a la depreciación del peso, lo que hacía imposible pensar en cambiar, de manera significativa, el mix monetariofiscal e impulsar un ajuste de gasto sin consecuencias importantes en el ciclo.

${ }^{3}$ Cabe mencionar que en el gobierno anterior de la Presidenta Bachelet el gasto aumentó 10,5 por ciento promedio anual.

${ }^{4}$ El Comité Fiscal Asesor (CFA) inició una reflexión respecto a cómo incorporar de la manera más adecuada en las decisiones de gasto eventuales cambios significativos en los parámetros estructurales. Una nota interna de E. Engel y J.P. Medina concluyó que había que hacerlo lo antes posible, en la medida en que no existieran costos de ajustar el gasto. 
Desde el punto de vista político, no obstante, era clave sustituir la meta de balance estructural en 2018 por otra que guiara y ordenara la política fiscal. Esto podría ser también leído como una suerte de compensación por el costo político de aplanar o hacer más graduales los compromisos de gasto e incluso abandonar algunos. Había que introducir gradualidad en todo: en los compromisos, en los gastos y en la convergencia del déficit.

El término "realismo sin renuncia" trató de resumir el desafío de ajustar expectativas. Aunque fue un concepto difícil de explicar (se entendió como un sí pero no o lo que en psicología se conoce como mensaje doble vinculante), significó un giro importante en la gestión del gobierno. Un largo consejo de gabinete en el estadio San Jorge a mediados de julio de 2015 y un cónclave con los partidos y parlamentarios de la Nueva Mayoría a comienzos de agosto en el estadio El Llano permitieron transmitir la racionalidad que sustentaba la nueva etapa de restricciones y la estrategia para sortearla.

También contribuyó a una mayor conciencia sobre la necesidad del cambio el escenario presentado en la actualización de proyecciones fiscales de mediados de año. El crecimiento esperado para 2015 disminuyó desde 3,6 por ciento a 2,5 por ciento (terminó siendo 2,1 por ciento) y el precio del cobre cayó desde US\$ 3,12 la libra a US\$ 2,75 la libra (y terminó en US\$2,50 la libra). Más importante, se proyectó un déficit de 3,3 por ciento del PIB, el mayor desde 2009 (terminó siendo 2,1 por ciento, gracias a más inflación e ingresos).

El presupuesto para 2016 tuvo tres elementos centrales: la implementación de una nueva meta para la regla fiscal, un sinceramiento importante en la promesa de construcción de hospitales y salas cunas, y la incorporación de algunas universidades, que no estaban en el Cruch, a la gratuidad, pero reduciendo el universo de acceso desde el anunciado 60 por ciento al 50 por ciento de vulnerabilidad.

La nueva meta de la regla fiscal trató de hacerse cargo de tres objetivos simultáneamente: (i) entregar una guía anual para la discusión del presupuesto, en particular respecto a cuánto se podía gastar, cuestión que se había abandonado en el gobierno anterior; (ii) hacer tangible la idea de consolidación fiscal gradual, y (iii) una estrategia fiscal robusta, en términos de no requerir modificaciones ante nuevos cambios en los parámetros estructurales. 
La implementación de esta nueva estrategia fiscal partió con la formalidad de un nuevo decreto supremo que, en septiembre de 2015, sustituyó la meta de converger a una situación de balance estructural en 2018 por una de mejoramiento gradual. Específicamente, se estableció que "la meta fiscal de la presente administración será, a partir del año 2016 y hasta 2018, reducir el déficit estructural en aproximadamente un cuarto de punto porcentual del PIB cada año, medido este último con parámetros estructurales comparables de un año a otro". Considerando los nuevos parámetros para el presupuesto de 2016, esto implicaba un aumento del gasto de gobierno de 4,4 por ciento y un déficit esperado de 3,2 por ciento para 2016 (en parte, por el aumento de recaudación esperada por la reforma tributaria).

El trámite parlamentario del presupuesto tuvo un foco importante en el avance en la construcción de hospitales y otra infraestructura para atención de salud. Se verificaban demoras significativas en la ejecución de los proyectos comprometidos (algo vergonzantes, considerando que se habían suspendido algunas concesiones hospitalarias a comienzos del gobierno) y gastos salariales no previstos y muy significativos en el sector salud (decididos unas semanas antes, para evitar un paro médico masivo), a los que había que hacer espacio cortando otros gastos. ${ }^{5} \mathrm{Me}-$ diando reasignaciones y acudiendo a soluciones creativas como el uso de fondos regionales, se logró acordar un cronograma fiscal y políticamente viable para avanzar en infraestructura de salud. El gasto en este ítem siguió aplanándose posteriormente, en especial a través del tamaño y complejidad de las obras.

El segundo punto de fricción fue el inicio de la gratuidad universitaria por glosa. La oposición recurrió al Tribunal Constitucional (TC) y éste falló estableciendo que la gratuidad era un derecho del estudiante que, en la práctica, debía ser portable entre instituciones que cumplieran ciertos requisitos de calidad. Esto restringió significativamente el diseño de los sucesivos avances de la gratuidad hacia nuevos segmentos de estudiantes e instituciones, y obligó a aprobar en acuerdo con la oposición una enmienda al presupuesto. Desde el punto de vista fiscal, reducir el avance al 50 por ciento fue un paso importante; también fue

${ }^{5}$ Algunos hospitales concesionados también han avanzado lentamente, por razones que son ajenas al concesionario, pero que deben tomarse en cuenta. Es necesaria una evaluación seria y desapasionada de este tema. 
constatar que, en la práctica, en la medida en que se mantuviera un aporte por gratuidad acotado, había instituciones privadas a las que simplemente no les convenía entrar al sistema porque cobraban aranceles muy por encima de los regulados.

Por otra parte, el reajuste del sector público en noviembre de ese año estuvo alineado con el sello de la austeridad. La negociación con la mesa de los gremios terminó sin acuerdo y se propuso al Congreso un reajuste de 4,1 por ciento, la última oferta realizada. La inflación venía disminuyendo desde 5 por ciento a mediados de año hasta 4 por ciento en octubre y los salarios privados crecían cerca de 6 por ciento. Lo más importante, sin embargo, fue una disminución significativa, a cerca de un tercio del gasto, en bonos de término de negociación. El gasto en bonos había escalado en los años previos y equivalía a casi 2 puntos porcentuales de reajuste. La disminución provocó bastante malestar a los dirigentes y dificultó la negociación al año siguiente. Congelar las remuneraciones más altas pudo haber sido percibido como populista, pero fue políticamente útil para aprobar el reajuste. ${ }^{6}$

A pesar de los esfuerzos, las perspectivas para la situación fiscal continuaron empeorando a fines de 2015, luego de sucesivas disminuciones en el precio del cobre, el que incluso bajó de los US\$ 2 la libra. Se hacía probable un déficit mayor a 3,5 por ciento del PIB y era crecientemente poco creíble que el precio del cobre de largo plazo fuera de US\$ 2,98 la libra, como había previsto el Comité Consultivo del Precio de Referencia del Cobre unos meses antes.

Para acotar los riesgos que este escenario generaba, se concretó un ajuste fiscal a fines de febrero de 2016. Previamente, se convocó nuevamente al Comité Consultivo, algo inédito hasta ese momento, que rebajó el precio de referencia hasta US\$ 2,57 la libra. Para mantener el objetivo de bajar el déficit estructural en un cuarto de punto, fue necesario cortar gastos por $\$ 380$ mil millones (aproximadamente US\$ 540 millones o 1 por ciento del presupuesto aprobado).

El discurso de la Cuenta Pública de 2016 se mantuvo en línea con las nuevas restricciones. Los medios reportaron que fue un 21 de Mayo

${ }^{6}$ No avanzó un proyecto que enviamos al Congreso, el cual entregaba más responsabilidad al Presidente para el reajuste de las rentas mayores y así eliminar el problema que enfrentan los parlamentarios frente a la opinión pública sobre reajustar la propia renta. 
sin grandes anuncios. Incluso se hizo algún mea culpa por el lento avance en la construcción de hospitales.

Una complicación fiscal particular fue el diseño de la reforma de educación superior que se envió al Congreso a mediados de 2016. El programa de gobierno consideraba llegar a la gratuidad universal en seis años (al 2020) y avanzar hasta el 70 por ciento de los hogares más vulnerables durante el gobierno. Pero calendarizar estos gastos implicaba desembolsar bastante más que los recursos disponibles. Las estimaciones eran que la gratuidad universal tendría un costo de casi 1,6 por ciento del PIB. Las otras reformas en educación ya costaban cerca de 1,5-1,6 por ciento del PIB en régimen, por lo que los gastos en régimen podían terminar siendo mucho mayores que el 2 por ciento del PIB previsto inicialmente.

Considerando este contexto, se planteó que los avances en gratuidad no fueran dependientes de un calendario predeterminado, sino de condiciones, específicamente de la razón entre ingresos estructurales y el PIB potencial, sobre un promedio que fuera más allá de un año. Se propuso que para financiar la gratuidad universal era necesario allegar del orden de 7 puntos del PIB adicionales como recursos permanentes y, además, el gasto en gratuidad sería sólo una fracción de esos nuevos ingresos. Por cierto, es opinable si corresponde amarrar así compromisos futuros, pero evidentemente es más responsable que legislar un calendario rígido de aumentos del gasto. En la sección siguiente se describe en detalle este tema.

La discusión del presupuesto para 2017 fue relativamente ordenada, considerando las restricciones. Se formuló con un crecimiento del gasto de 2,7 por ciento siguiendo estrictamente la nueva meta fiscal. El tema más complejo fue la negociación con la oposición para avanzar en gratuidad a centros de formación técnica (CFT) e institutos profesionales (IP), de modo de no terminar nuevamente en el Tribunal Constitucional. La negociación llevó a abrir el acceso a becas al mundo no Cruch, lo que fue criticado por la izquierda de la Nueva Mayoría (NM). También por primera vez se manifestaron fuertes demandas por mayores fondos para investigación y desarrollo, que se acomodaron con reasignaciones.

El presupuesto también contempló recursos por más de US\$ 100 millones para aumentar el pilar solidario de pensiones en 10 por ciento. 
El tema de las jubilaciones estaba candente y los partidos de gobierno consideraban que este gasto era urgente. Tomando en cuenta la restricción de recursos, se acordó que el reajuste salarial del sector público contribuyera al espacio presupuestario necesario. A pesar de los montos involucrados y de que era el primer reajuste del pilar desde su creación, tuvo escaso impacto y para el tema de pensiones fue como una gota en el mar. El reajuste salarial, en cambio, desató un gallito mayor.

Existía el convencimiento en los equipos de Hacienda de que mantener los salarios creciendo a un ritmo moderado era clave para sostener una tasa de desempleo baja, por lo que era necesario intentar un reajuste acotado. El esfuerzo de contención desató un paro del sector público de tres semanas y rechazos sucesivos del proyecto de ley por parte de la Cámara de Diputados. Sólo terminó con un veto aditivo por parte de la Presidenta, el que mantuvo el guarismo inicial de 3,2 por ciento (con una inflación acumulada en 12 meses de 2,9 por ciento a noviembre) e incluyó cambios marginales en los demás beneficios. Fue un esfuerzo de contención valioso, pero políticamente costoso.

La Cuenta Pública de 2017, que se realizó por primera vez el 1 de junio, se focalizó en los avances en distintas áreas (en comparación con el gobierno anterior) y consideró pocos anuncios nuevos, aunque la presión para otros gastos tuvo la habitualidad de siempre. La Presidenta ratificó el avance de la gratuidad en educación superior al 60 por ciento en 2018 y los anuncios más relevantes fueron proyectos de largo plazo: una nueva línea de metro y embalses que se concesionarían.

Durante estos años la deuda del sector salud fue un problema recurrente y sin solución. Los hospitales y los servicios de salud gastan más que su presupuesto asignado, lo que dificulta enormemente cualquier planificación (ver Ahumada et al. 2016). Aunque las razones de este sobregasto son diversas, en la práctica esto termina en que son los proveedores del sistema - los acreedores - quienes controlan implícitamente el gasto a través de regular cuánta deuda están dispuestos a financiar. Cada vez que la Dirección de Presupuestos (Dipres) cancelaba parte de esta deuda, el gasto y la deuda volvían a aumentar. Las restricciones de endeudamiento de parte de los proveedores ponen el límite, no el presupuesto, con todos los costos de eficiencia que esto implica. Los montos llegaron a ser significativos desde el punto de vista macro-fiscal. Por ejemplo, en 2015 se sobreejecutó el presupuesto de los servicios de sa- 
lud en más de 17 por ciento. Para 2017, de acuerdo a la presentación del Informe de Finanzas Públicas, el gasto total creció más de 0,2 puntos porcentuales por esta sobreejecución.

\subsection{Algunas métricas de desempeño}

Los resultados de estos esfuerzos fueron en general positivos, aunque no exentos de problemas. El gasto se alineó con la nueva meta en cada presupuesto, y aunque creció, lo hizo significativamente menos que lo considerado en el programa de gobierno. La deuda pública aumentó - como era predecible, dada la regla fiscal y el comportamiento de la economía-, y las clasificadoras decidieron hacer un recorte en nuestra nota de riesgo crediticio en 2017. Con todo, el premio pagado por riesgo país (lo que los inversionistas nos cobran en tasa de interés por encima de Estados Unidos) se mantuvo controlado y a la baja, más allá de algunos cambios transitorios asociados a las condiciones globales.

El shock de ingresos que enfrentó el gobierno fue considerable. Por un lado, los ingresos fiscales efectivos por el cobre, en promedio cada año, fueron 2,5 por ciento del PIB menores durante el periodo 20142017 que en el 2010-2013. Por otro lado, el menor crecimiento efectivo respecto del proyectado significó una merma promedio de 1,4 por ciento del PIB cada año (y de 2,4 por ciento en 2017). Esto se compara, por ejemplo, con un gasto fiscal de 0,6 por ciento del PIB promedio por año causado por el terremoto del 27F, entre 2010 y 2013. De esta manera, la sola disminución del precio del cobre significó perder un monto de recursos cuatro veces mayor que el destinado a enfrentar el terremoto de 2010.

A pesar de lo anterior, a partir de 2015 los déficits fiscales efectivos fueron menores que los proyectados, en parte porque los ingresos tributarios sorprendieron al alza. El déficit estructural disminuyó gradualmente entre 2015 y 2016, en línea con la regla y nuestro objetivo fiscal. Si se consideran los parámetros estructurales del presupuesto 2018, la reducción fue algo menor que la estimada. Pero con los parámetros del presupuesto de 2017, las disminuciones del déficit en 2016 y en el presupuesto de 2017 fueron en torno a un cuarto de punto del PIB de cada año.

Cabe destacar también que la razón del gasto a PIB tuvo un aumento moderado a partir de fines de 2015 (gráfico 1). Y si bien el déficit fiscal se incrementó casi 2 por ciento del PIB desde marzo de 2014, lo 
Gráfico 1. INGRESOS Y GASTOS FISCALES (\% PIB, últimos 12m)

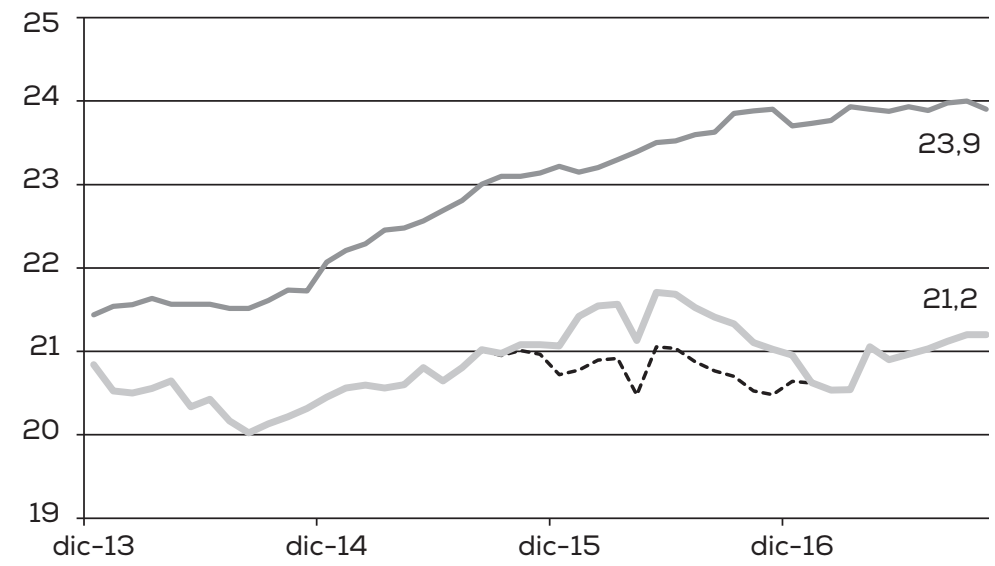

Gastos

-.---.- Ingresos sin registro de capitales (RC) Ingresos

Último dato: octubre 2017.

Fuente: Dipres.

Gráfico 2. BALANCE EFECTIVO Y SIN COBRE (\% PIB, últimos 12m)

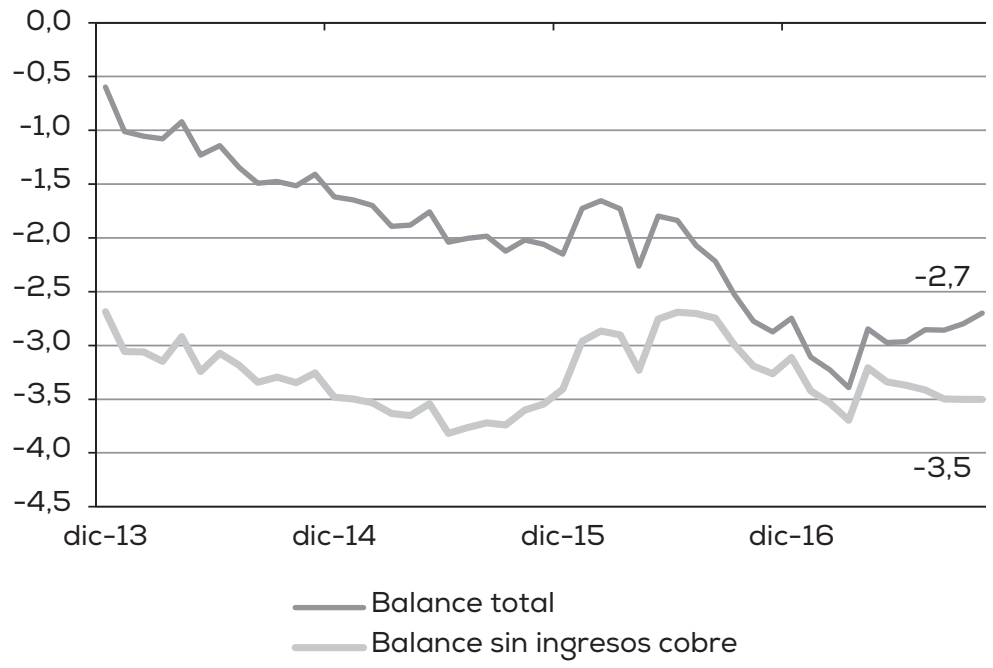

Último dato: octubre 2017.

Fuente: Dipres. 
hizo en menos de un punto desde mediados de 2015, mientras el déficit excluido el cobre dejó de deteriorarse desde ese tiempo (gráfico 2).

Parte de estos logros responde a mayores ingresos no recurrentes, aunque también se debe considerar que algunos ingresos, que proveería la reforma tributaria, demoraron en materializarse. Específicamente, la base tributaria de las empresas-no-cobre tuvo una baja significativa y anormal en 2016, en parte por una importante disminución de utilidades durante ese año, de empresas con operaciones en Argentina y Brasil. El presupuesto de 2018 supuso una reversión de esta caída.

Los resultados fiscales son bastante favorables si se comparan con los de otros países. Consideramos aquí los países sudamericanos más relevantes y un grupo de exportadores de materias primas. ${ }^{7}$ Respecto del primer conjunto, el aumento del déficit fiscal de Chile fue moderado (gráfico 3). Sólo Uruguay no tuvo una ampliación notoria del déficit, aunque partió de un nivel de déficit y deuda abultados. El aumento de la deuda chilena tampoco parece alto en este grupo de países (gráfico 4).

En el conjunto de países exportadores de materias primas se aprecia más heterogeneidad, aunque Chile no aparece como un caso excepcional (gráfico 5). En un extremo está el fuerte cambio en el balance de Arabia Saudita. En el otro, algunos países en que el gobierno no es dueño del recurso natural o tenían más deuda o déficit. Dado el nivel de deuda de Chile (gráfico 6), parece natural que acomodara un mayor déficit.

S\&P y Moody's asignaron primero una perspectiva negativa y luego rebajaron la clasificación de riesgo de Chile durante 2017, modificando la perspectiva de negativa a estable. Fitch cambió la perspectiva a negativa, pero no ha tomado acción hasta este momento. Estas decisiones fueron un fuerte llamado de atención. Si bien obedecieron al menor crecimiento y no directamente a la estrategia fiscal, que apoyaron de manera explícita, fue igual un punto negro en la gestión fiscal. Los efectos en las tasas de interés y riesgo país fueron muy marginales, probablemente porque desde hace tiempo los mercados consideraban a Chile por debajo de un rating AA.

Más allá de los efectos de mercado, que fueron mínimos, los downgrade evidenciaron dos aristas complicadas: para empezar, era la primera vez que ocurrían desde que Chile tiene acceso normal a los mercados. Y a continuación, algunos países de la región que enfrentaron

\footnotetext{
${ }^{7}$ Los datos son del Fiscal Monitor del FMI, de octubre de 2017.
} 
Gráfico 3. SUDAMÉRICA: DÉFICIT FISCAL 2013 y 2017 (\% PIB)

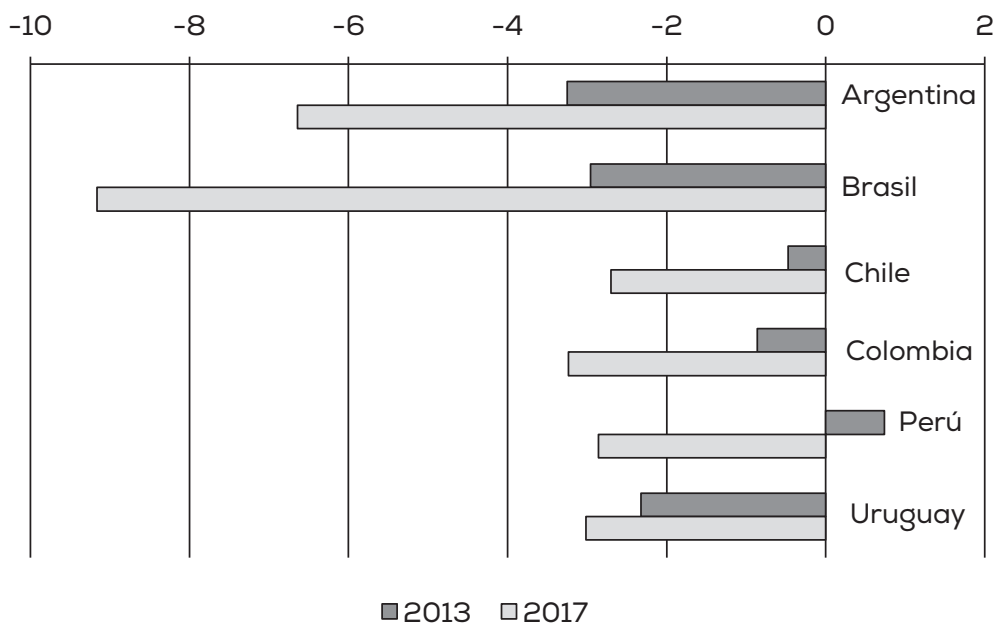

Fuente: Elaboración propia en base a datos del Monitor Fiscal del FMI.

Gráfico 4. SUDAMÉRICA: DEUDA PÚBLICA 2013 y 2017 (\% PIB)

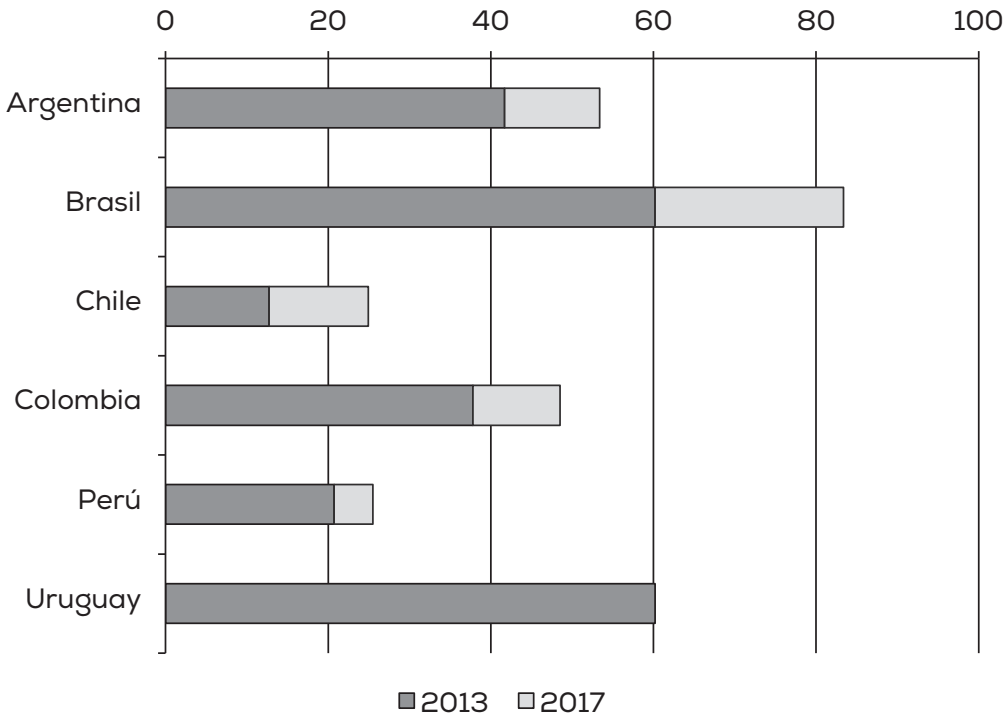

Fuente: Elaboración propia en base a datos del Monitor Fiscal del FMI. 
Gráfico 5. EXPORTADORES DE MATERIAS PRIMAS: DÉFICIT FISCAL EN 2013 Y 2017 (\% PIB)

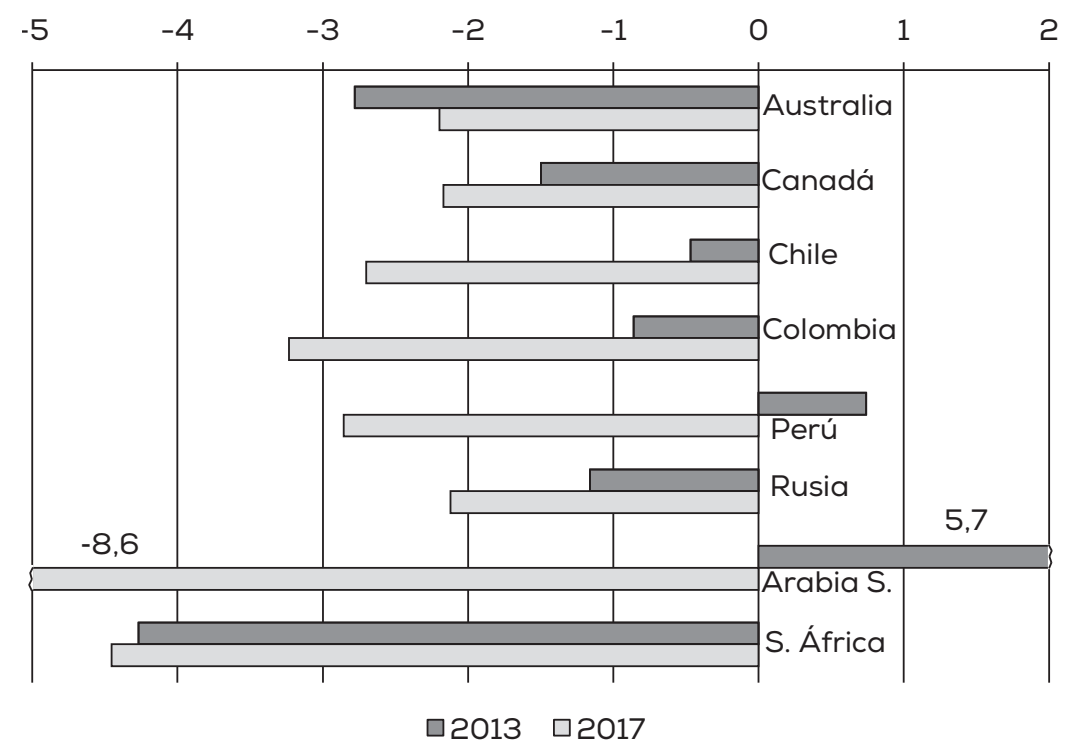

Fuente: Elaboración propia en base a datos del Monitor Fiscal del FMI.

Gráfico 6. EXPORTADORES DE MATERIAS PRIMAS: DEUDA PÚBLICA EN 2013 Y 2017 (\% PIB)

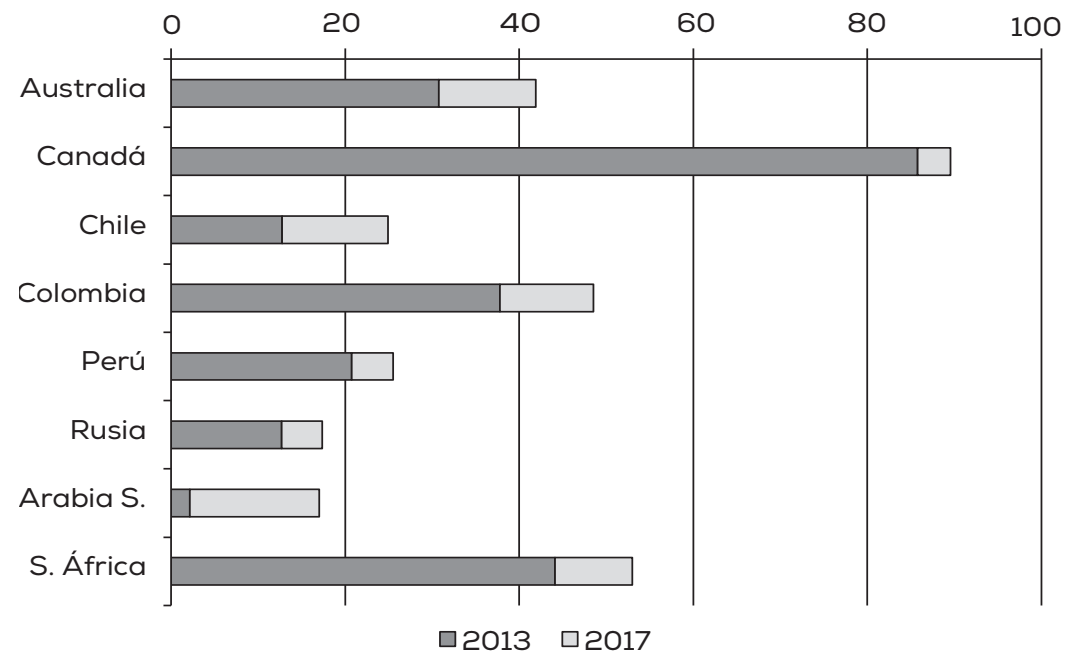

Fuente: Elaboración propia en base a datos del Monitor Fiscal del FMI. 
Gráfico 7. DEUDA Y PAGO DE INTERESES EN CHILE (\% PIB)

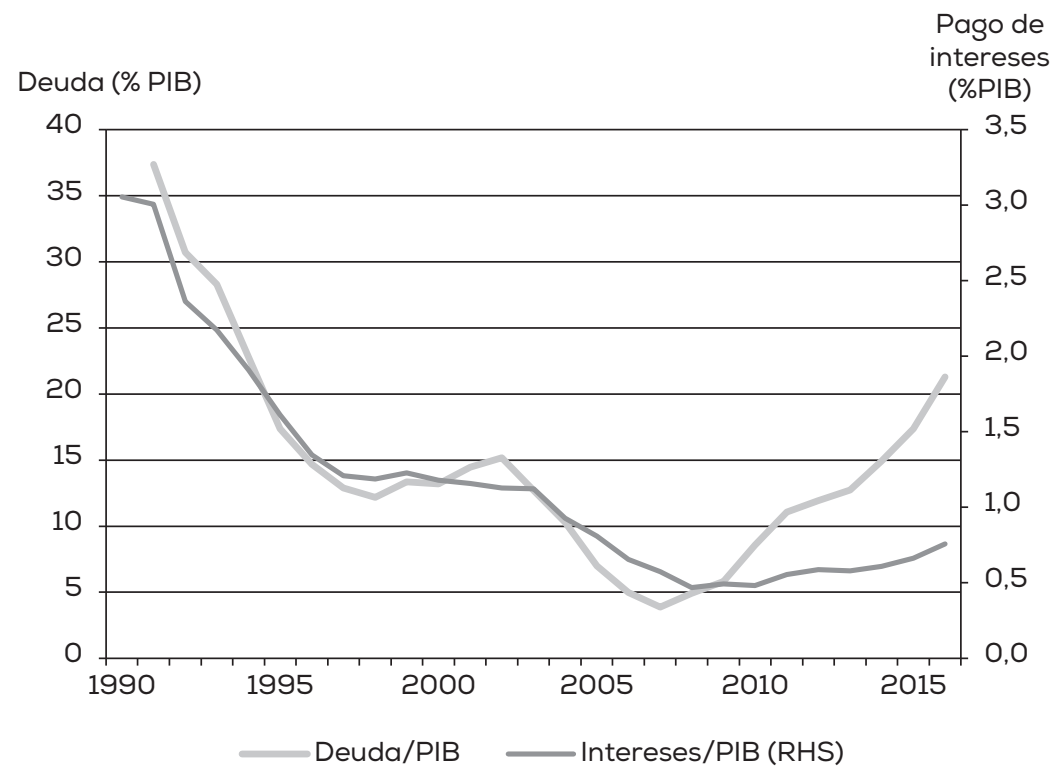

Fuente: Dipres y Banco Central de Chile.

Gráfico 8. RIESGO PAÍS EMBI GLOBAL (PUNTOS BASE SOBRE BONO EE.UU.)

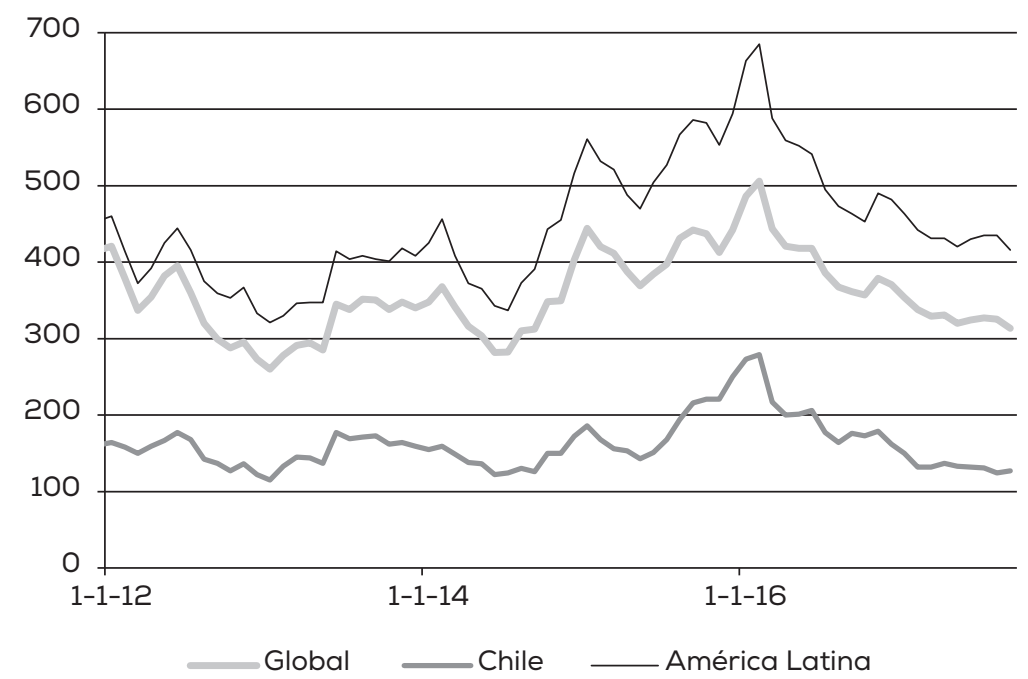

Fuente: Dipres y Banco Central de Chile. 
problemas similares a los nuestros lograron evitarlos, lo que sugería que nuestra política fiscal había tomado riesgos. Con todo, fue importante que se le otorgara al país una perspectiva estable, lo que sugiere que, de perseverar en las políticas aplicadas en este periodo, no deberían existir nuevas rebajas.

La deuda pública aumentó y probablemente se estabilice algo por debajo de 30 por ciento en los próximos años, si se mantiene la estrategia de consolidación actual. Si bien este aumento es relevante, cabe destacar que el gasto en intereses ha crecido poco y sigue muy por debajo al registrado en las dos décadas pasadas (gráfico 7). El spread soberano, medido por el Emerging Markets Bond Index (EMBI), siguió todo este tiempo a una distancia relativa similar o incluso mayor que en el pasado respecto de otros países, y es menor a fines de 2017 que el registrado en 2014 (gráfico 8). Este mejor desempeño de Chile relativo a otros países es aún más notorio si se consideran los llamados Credit Default Swaps (CDS, o seguros de riesgo de impago).

\subsection{Mirando hacia adelante}

Existe una variedad de temas fiscales relevantes para los próximos años a los que es necesario poner atención, incluyendo el avance y diseño de la descentralización, eventuales cambios constitucionales con potenciales efectos en el gasto y el problema previsional. Esta sección, sin embargo, centra la discusión en algunos temas más directamente ligados a la administración fiscal: el (re)diseño de la regla fiscal, algunos gastos que están creciendo más rápido sin contraparte aparente en resultados, el rol del Consejo Fiscal Asesor y una propuesta de cambio simple del calendario de eventos políticos que ayudaría a una mejor gestión. $^{8}$

${ }^{8}$ Adicionalmente, hay dos temas técnicos específicos de contabilidad pública que conviene mirar a futuro: (i) el incentivo a descapitalizar las empresas públicas que produce el hecho de que los dividendos sean un ingreso sobre la línea y que se pueda capitalizar con operaciones bajo la línea, y (ii) algunas anotaciones bajo y sobre la línea (como gastos o transacciones de activos financieros) que debieran registrarse de manera diferente, especialmente el crédito con aval del Estado para la educación superior y una serie de garantías crediticias que otorga la Corfo. Sería adecuado calcular y anotar las provisiones como gasto arriba de la línea y todas las transacciones de activos debajo de la línea. 


\subsubsection{La regla fiscal}

La regla fiscal basada en cálculos estructurales ha sido de gran utilidad desde que se implementó en 2001. Sin embargo, ha sufrido períodos de estrés que han generado lecciones importantes que se deben evaluar e incorporar.

La primera es la conveniencia de proponer metas anuales. Tener sólo un objetivo a fines de gobierno, como se hizo en 2010-2014 y al comienzo de la administración Bachelet, deja la discusión presupuestaria anual sin un ancla efectiva. Se puede defender que en 2010 no era obvia la posición fiscal y se necesitaba flexibilidad, pero es importante que exista una racionalidad clara que sustente la decisión de cuánto aumenta el gasto en cada discusión presupuestaria.

Lo anterior facilita enormemente la coordinación monetaria-fiscal. Tener que proyectar qué hará la autoridad fiscal con uno o dos años de anterioridad es una complicación adicional para las decisiones del Banco Central y deja, además, cierta responsabilidad del manejo cíclico al fisco en los primeros años de gobierno. Ejemplo de lo anterior lo constituye la combinación de la expansión presupuestaria de casi 10 por ciento en 2015, discutida en 2014, y el alza de tasas de interés de la segunda mitad de 2015. La regla fiscal chilena nació para evitar la pro ciclicidad de una regla nominal (y de aquellas que se basan en comparar el aumento del gasto con el crecimiento del PIB), pero nunca se concibió como una herramienta contracíclica relevante. ${ }^{9}$

Dos años después de anunciada, algunos analistas expresaron reparos respecto a que la regla implementada se expresara sobre un cambio del déficit (y no sobre un nivel absoluto), y que utilizara "parámetros comparables" entre años, eso es el mismo precio de referencia del cobre y una misma cosecha del PIB potencial. Si bien existía la posibilidad de tener un objetivo de nivel estructural para cada año, dada la volatilidad paramétrica que se enfrentaba, el riesgo era significativo. ${ }^{10}$ Una política

${ }^{9}$ Es posible que sea adecuado tener una cláusula de escape para casos excepcionales, como cuando se llega al límite cero para la tasa de interés de política monetaria. También, un seguro para agentes con restricciones de liquidez, como se argumenta en Engel et al. (2010).

${ }^{10}$ Es interesante el paralelo entre esta discusión y aquélla en política monetaria respecto de objetivos de inflación versus nivel de precios. El Comité Asesor para el Diseño de una Política Fiscal de Segunda Generación para Chile (Corbo et al. 
fiscal que obligara a cerrar cualquier desviación estructural en un año, porque, por ejemplo, el precio del cobre de largo plazo cambiaba, tenía costos macro y microeconómicos (y obviamente políticos) importantes. Eso se alejaba de cualquier posibilidad de reacción sensata.

El diseño consideró un ajuste gradual que garantizaba sostenibilidad en el largo plazo. Ciertamente se podría haber considerado un esfuerzo fiscal mayor si el déficit efectivo o la deuda resultaban mayores que lo esperado, pero no parecía necesario dado el horizonte de sólo tres años y las dificultades comunicacionales que implicaba tener un objetivo contingente. En todo caso, en el equipo de Hacienda se pensaba que, cualquiera fuera la circunstancia, traspasar un déficit nominal mayor a 3,5 por ciento del PIB era un riesgo que debía evitarse a toda costa.

En los próximos años, es posible volver a un objetivo absoluto anual, pero probablemente sea mejor mantener la flexibilidad que otorga una regla de mejoramiento gradual con parámetros comparables hasta converger a un nivel de déficit deseado (en vez de un objetivo de nivel incondicional a lo que suceda).

Si en algún momento se vuelve a un objetivo absoluto anual, parece necesario mantener una cuenta auxiliar que permita "devolver" desviaciones por cambios exógenos, como ajustes paramétricos o shocks en el nivel de precios, de manera gradual (como es el caso de la regla fiscal alemana). También parece apropiado, cuando se llegue a un estado de régimen, explicitar una cláusula de escape en casos de crisis, como lo propuso la Comisión Corbo.

Se ha propuesto en algunos círculos un techo legal para la deuda como por ciento del PIB; por ejemplo, de 35 por ciento. La idea me parece riesgosa. Es probable que ese número actúe como imán y que, llegado a ese nivel, o no se respete el techo o simplemente lleve a una política pro cíclica, eliminando la amortiguación que otorga el objetivo estructural. La experiencia europea, con el Tratado de Maastricht, es un fuerte llamado de atención frente a esta propuesta.

2011, 7) recomendó que "frente a cambios significativos en algún parámetro clave, que hagan variar considerablemente los ingresos cíclicamente ajustados, el Ejecutivo considere alternativas para complementar la regla con mecanismos de ajuste parcial, que permitan suavizar la convergencia hacia un nuevo equilibrio de largo plazo". 
En otro ámbito, parece deseable que la discusión fiscal tenga un foco más fuerte en el balance efectivo y estructural, y en la dinámica de la deuda pública. La lucha ideológica sobre el tamaño del Estado en Chile hace que la discusión se focalice excesivamente en el crecimiento del gasto y su comparación con el del PIB, perdiéndose de vista toda la acción macroeconómica que producen los cambios de ingresos. En la gran mayoría de los países se entiende que una política fiscal es más bien expansiva si el déficit aumenta, y es particularmente expansiva si aumenta el déficit estructural. En Chile, se puede llegar al punto de que si el gasto crece menos que el PIB, se considera una política cuidadosa o contractiva (cuestión que no es así si el PIB crece sobre el potencial). Al mismo tiempo, pareciera que cambios impositivos no importaran para el impulso fiscal.

\subsubsection{Eficiencia en el gasto}

Respecto de las partidas presupuestarias relevantes que ofrecen espacio para más eficiencia, cabe destacar el significativo aumento relativo de las partidas de salud (gráfico 9), que contrasta con la pobre percepción que existe respecto de la calidad de la atención, al tiempo que es un sector que enfrenta, como se comentó antes, problemas de manejo presupuestario como ningún otro.

El sector educación también ha ganado participación en el presupuesto a través de los años (gráfico 10). Esto, sin embargo, parece haber sido una decisión más explícita $\mathrm{y}$, al menos de acuerdo a las últimas encuestas, no se percibe como un sector con carencias urgentes. El espacio lo ha creado la reducción del gasto en vejez (específicamente, pensiones), por la gradual maduración del cambio de sistema a capitalización. El gasto en funciones relacionadas con la economía (como los subsidios a sectores y el presupuesto de la Corfo), que es otro relevante en cuanto a volumen, se ha mantenido más estable.

Es interesante también notar la disminución relativa del presupuesto para defensa (con los gastos por Ley Reservada del Cobre ocurre algo parecido. Ver gráfico 9). La idea según la cual se pueden financiar grandes partidas disminuyendo el presupuesto en defensa es un espejismo. En lo reciente, su tamaño absoluto y relativo no es particularmente elevado. En cierta manera, ya se usó ese espacio. 
Gráfico 9. GASTO FUNCIONAL 1990-2016: SEGURIDAD, SALUD Y DEFENSA (\% DEL TOTAL)

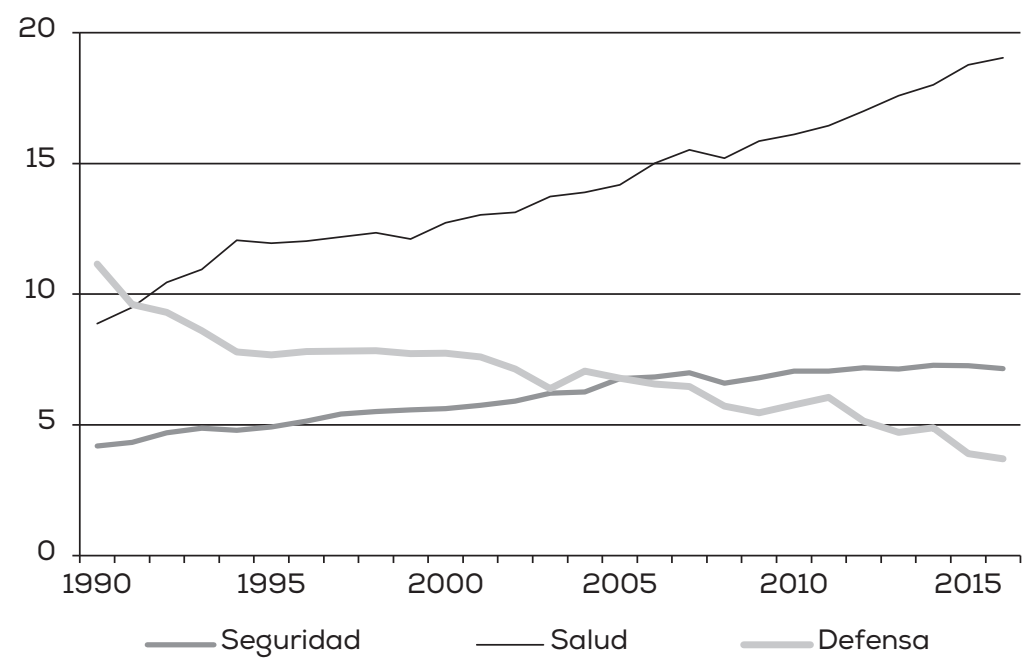

Fuente: Dipres.

Gráfico 10. GASTO FUNCIONAL 1990-2016: ECONOMÍA, EDUCACIÓN Y VEJEZ (\% DEL TOTAL)

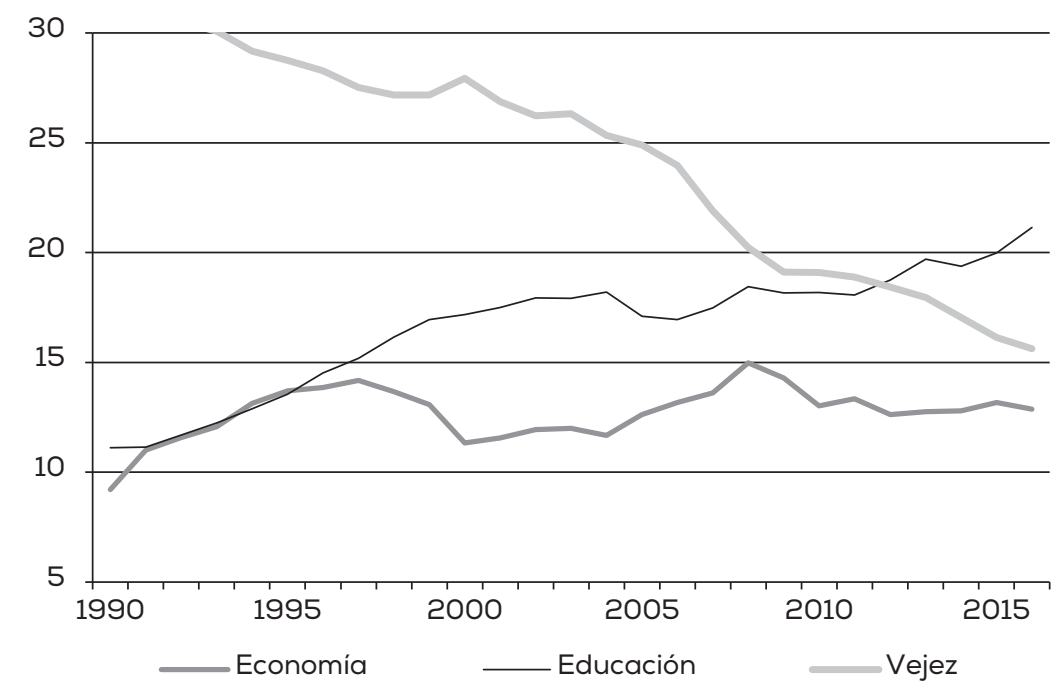

Fuente: Dipres. 
Las implicancias respecto de salud son obvias, pero difíciles de implementar. Es necesario revisar la organización y gestión del sector. La deuda hospitalaria es una anomalía grave, que debe ser subsanada. Y, contrario a lo que algunos piensan, es improbable que se solucione con más recursos. La calidad de la gestión y logística hospitalaria también necesitan particular atención.

Lamentablemente, lo anterior también topa con la gestión de recursos humanos en el Estado. Los gremios hacen su trabajo de puja en un marco desregulado (incluso con una prohibición constitucional de huelga), con incentivos muy negativos: parar casi no tiene consecuencias, a pesar de los esfuerzos de la Contraloría y de los equipos de conflictos para descontar sueldos. A final, sólo la presión del público impone algo de disciplina. Pero esto es casi imposible de manejar para un gobierno en el caso de la salud, en que el costo social y político de los paros son muy altos. Y se hace más difícil si los gremios perciben que el gobierno es débil o los directivos intermedios están más cerca de los partidos políticos que del gobierno.

Es necesario cambiar las reglas de cómo se negocian salarios en el sector público. El ideal sería tener acuerdos que duren más de un año, que permitan diferenciación entre estamentos y sectores, y, más importante, que se regule el paro como cualquier huelga, incluyendo la provisión de servicios mínimos robustos con reemplazo. Por supuesto, esto también requiere modificar las normas de inamovilidad. Urge, asimismo, terminar con la práctica de un reajuste general y luego mejoras sectoriales disfrazadas de "modernizaciones", habitualmente hechas bajo presión.

Aunque los reajustes salariales generales de los últimos años fueron modestos, el gasto salarial creció considerablemente. Contra las creencias habituales, sólo una parte del mayor gasto responde a nuevas contrataciones. Más importante fueron los mejoramientos salariales sectoriales, la mayor parte de las veces bajo amenazas o materialización de paros en servicios en que eran políticamente costosos (como en salud, Registro Civil y la Dirección de Aeronáutica). A ello se suman incentivos al retiro y, especialmente, "modernizaciones" de plantas asociadas a cambios institucionales. El margen de contrataciones está finalmente bastante controlado por la Dipres, pero el salarial es mucho más sensible a las presiones políticas. 


\subsubsection{Rol del Consejo Fiscal Asesor}

Respecto de ideas que se discuten sobre el Consejo Fiscal Asesor (CFA) del Ministerio de Hacienda, es importante reconocer el avance gradual en sus atribuciones, algo que ha servido a un propósito básico: debe existir confianza en que los cálculos del balance estructural son correctos. El último cambio fue darle al CFA un rol central en el nombramiento de los comités de expertos independientes que calculan el precio del cobre de largo plazo y el PIB tendencial. Es posible entregar más elementos para lo mismo: más independencia, más influencia sobre el calendario de la citación de las comisiones y de los cálculos del balance estructural, y, posiblemente, un espacio más amplio de opinión.

Sin embargo, otorgarle al CFA poder resolutivo sobre qué hacer con la orientación de la política fiscal sería un error. Ésa es una decisión política que debe estar radicada en el Ejecutivo, sin ambigüedades. Hay buenas razones para que la política monetaria esté en manos de un órgano independiente, en especial por el riesgo de inconsistencia dinámica y su implicancia para la inflación promedio. Estas razones, pienso, no se aplican tan fácilmente a la política fiscal, lo que hace poco razonable entregar estas herramientas a autoridades no elegidas en el proceso democrático.

\subsubsection{Un nuevo calendario electoral}

Finalmente, respecto del calendario elecciones-presupuesto, es evidente que un período presidencial de cuatro años es un lapso relativamente corto. Si esto no se modifica, igual se ganaría bastante adelantando o retrasando las elecciones por una vez para, digamos, mediados de año. En la actualidad hay sólo tres presupuestos que elabora y ejecuta un gobierno, cuya duración ya es acotada. Este cambio permitiría que fueran cuatro y que las elecciones fueran antes de la discusión presupuestaria.

También sería un avance mover la Cuenta Pública Presidencial más cerca de la presentación del presupuesto. En la actualidad, estos son los dos eventos que generan expectativas de anuncios, con la obvia presión fiscal. La Cuenta debería ocurrir unos días antes de la presentación del presupuesto y constituir un ejercicio de revisión, pero también de alineamiento más claro de la política fiscal con las prioridades políticas. La fecha del 21 de mayo (y ahora 1 de junio) se arrastra del tiempo 
en que existían dos períodos en el Congreso: el de sesiones ordinarias y el de extraordinarias, cada uno con distintas reglas sobre temas e iniciativas. En la actualidad, estas fechas no tienen sentido y el discurso podría tener un foco de gestión más claro si se hiciera más avanzado el año. Incluso, se podría agregar un quinto evento a fines de cada gobierno, que tenga sólo la característica de cuenta, unos meses antes de terminar.

\section{TRES REFORMAS EMBLEMÁTICAS (Y COMPLEJAS)}

Desde su inicio, la segunda administración Bachelet mostró una ambición reformista mayor que los gobiernos anteriores, aunque durante los gobiernos de la Concertación también hubo muchos cambios. Respondiendo al diseño recogido en el programa de gobierno, se impulsaron varias transformaciones, cuyos ejes principales fueron una reforma tributaria significativa, un conjunto de cambios profundos en educación y una nueva constitución. Pero también se aprobaron reformas al mercado laboral, al financiamiento de la política y al sistema de elecciones, y se envió una propuesta para modificar y fortalecer el sistema de pensiones. Esta sección revisa las reformas tributaria, laboral y educacional.

\subsection{La reforma tributaria}

El programa de gobierno propuso un cambio profundo del sistema tributario. Se planteó recaudar del orden del 3 por ciento del PIB, lo que llevaría nuestra carga tributaria al promedio de los países OCDE, considerando la carga que existía en cada país cuando su PIB per cápita equivalía al que Chile tenía en 2014 (excluyendo ingresos por los aportes de pensiones dado el sistema imperante en Chile). Si bien la ley de Wagner (que asocia positivamente el tamaño del Estado con el nivel de PIB) provee una referencia útil, es necesario también calibrar un aumento de la carga tributaria dados los costos en eficiencia que provocan los impuestos.

Otros objetivos de la reforma fueron hacer al sistema más progresivo, reducir tratamientos especiales (como el IVA a la construcción y la renta presunta) y encarecer algunos "males", como el consumo de ciga- 
rrillos, alcoholes y bebidas azucaradas; así como la emisión de carbono. También se potenciaría la capacidad del Servicio de Impuestos Internos (SII) para disminuir la evasión y elusión.

El proyecto original que se envió al Congreso incluía como eje central cambiar el sistema basado en la tributación integrada de las empresas y personas, con cobros por distribuciones efectivas de las ganancias (que se acumulaban en el llamado Fondo de Utilidades Tributables, FUT), a uno también integrado, pero con base devengada. Para ello sería necesario "atribuir" ganancias a los socios de una empresa de manera que pagaran sus impuestos. Además del cambio de mecanismo, se proponía aumentar la tasa del impuesto a las utilidades corporativas de 20 a 25 por ciento. También se planteó disminuir la tasa máxima de impuesto a las personas y fortalecer el sistema simplificado para pequeñas empresas, basado ahora en la tributación al flujo de caja.

La discusión en el Congreso - junto con ciertas dudas técnicas de algunos expertos relativas a que el sistema atribuido se pudiera implementar en forma exclusiva- llevó a un acuerdo con la oposición en 2014 que modificó este aspecto. Se legisló un tercer sistema, alternativo y voluntario, en el cual los pagos de impuestos a nivel de empresa serían parcialmente acreditados para el impuesto a las personas y este tributo se pagaría sólo cuando las utilidades se distribuyeran (no cuando se devengaran). Este régimen se denominó sistema parcialmente integrado, pues una parte funciona como un sistema desintegrado en que los pagos de impuestos de la firma y el ingreso de los dueños no tienen conexión (como ocurre en una mayoría de los países de la OCDE). En este caso, las empresas estarían gravadas con una tasa de 27 en vez de 25 por ciento, $\mathrm{y}$, además, el 65 por ciento de lo pagado podría imputarse como crédito para el pago del impuesto personal cuando la utilidad se distribuyera.

Aunque la reforma tenía una aplicación gradual y la entrada en vigencia del nuevo sistema parcialmente integrado ocurriría recién en 2018, cuando asumí como ministro en 2015, entre los círculos de economistas y tributaristas, había cierto consenso en cuanto a que el acuerdo gobiernooposición había dejado un sistema en extremo complicado y que podría ser inaplicable. En paralelo, el mundo empresarial, que había tenido una actitud de rechazo permanente a los cambios, estaba levantando un conjunto de aspectos prácticos que implicaban riesgos para el buen funciona- 
miento del sistema tributario. En general, la aprensión de diversos sectores era que la atribución era casi imposible en una cascada de sociedades y en estructuras circulares de propiedad. Si además se mezclaban los sistemas atribuido y semi-integrado, el resultado era impredecible.

Simplificar el sistema, sin embargo, no era fácil en términos técnicos ni tampoco desde la óptica política. "Reformar la reforma" significaba pagar costos políticos importantes; había que hacerlo manteniendo la misma recaudación, que ésta recayera más o menos en los mismos agentes y sectores económicos, y que los cambios se aprobaran en un tiempo reducido. Con todo, se resolvió impulsar una propuesta de ajuste acotada y quirúrgica, ya que si la agenda económica seguía capturada por este tema implicaría entrar en un pantano.

El proyecto de ley enviado al Congreso abordó una simplificación acotada a través de restringir la posibilidad de escoger el sistema atribuido y la simplificación a pequeñas y medianas empresas (pymes), limitada a organizaciones cuya malla societaria fuese simple (socios, propietarios o accionistas que fueran exclusivamente personas naturales contribuyentes del impuesto global complementario). También se perfeccionó una serie de aspectos de la reforma inicial, incluyendo una simplificación de las cuentas que sustituían el FUT y precisiones para los cambios a la tributación del IVA en la construcción de viviendas. Debido a su complejidad, la preparación del proyecto tomó más tiempo del esperado y el texto terminó siendo incluso más extenso que la reforma original. Pero la demora permitió un valioso diálogo técnico con los principales actores involucrados, que facilitó su posterior aprobación en enero de 2016.

Junto con la simplificación (y aplicabilidad) de los cambios en materia tributaria, se hizo un giro comunicacional importante. Durante el primer año de gobierno se argumentó que los mayores impuestos los pagarían sólo los más ricos ("los poderosos de siempre") y, más importante, que los cambios no tendrían impactos en la inversión y en el crecimiento. Esto tuvo un efecto importante en la confianza del empresariado. En el debate sobre el proyecto de simplificación, argumentamos que aumentar los impuestos a las empresas tiene efectos, ya que eleva el costo del capital. Probablemente eran efectos acotados y transitorios, pero no eran cero. No era un "almuerzo gratis", sin costos. Era un esfuerzo que se les pedía a los chilenos, en especial a los más ricos, para 
financiar reformas que eran justas y claves para el crecimiento de largo plazo, como mejorar la educación.

¿Cómo ha funcionado la reforma y su simplificación? Hasta 2017, hay sólo cambios de tasas impositivas y bases tributarias, por lo que no es posible evaluarla por completo. Recién durante 2018 habrá información sobre la interacción de los sistemas.

Gradualmente, los contribuyentes y el sistema de apoyo se han ido adaptando. A mediados de 2017, había 302 mil pymes que habían escogido el sistema simplificado 14 TER. Asimismo, las empresas terminaron su proceso de escoger entre los nuevos dos sistemas, con cuatro veces más empresas en el régimen atribuido. Como se explicó en la sección anterior, la recaudación proveniente de las empresas ha sido algo más baja que lo esperado, especialmente porque la base tributaria de las firmas del sector no cobre disminuyó fuertemente en 2016. Pero es prematuro asignarlo a la reforma.

Existe un aprendizaje particularmente útil proveniente del régimen transitorio que se estableció para acelerar retiros de utilidades empozadas en el FUT (el llamado impuesto sustitutivo al FUT, o ISFUT). Como se sabe, se estableció un régimen transitorio que permitió retirar pagando por una sola vez o una tasa única de 32 por ciento menos los créditos del respectivo FUT, o bien la tasa promedio del global complementario de los últimos años menos el mismo crédito. Este mecanismo permitió una recaudación relevante, pero también mostró que hay muchos contribuyentes que, siendo personas naturales y recibiendo rentas del capital, pagan tasas muy reducidas (gráficos 11 y 12). El mecanismo que parece ser más común es dividir los retiros entre varios dueños (habitualmente, miembros de la misma familia).

El efecto es preocupante: la tasa adicional que pagan estas personas es en promedio de 2 a 3 por ciento, mientras que entre la tasa máxima del global complementario y las tasas históricas pagadas existe una diferencia de más de 20 puntos porcentuales. La realidad es que las rentas del capital pagan una tasa relevante a nivel corporativo, pero casi insignificante a nivel de personas. Esta realidad también se aprecia en el porcentaje de contribuyentes que, recibiendo dividendos, están en los tramos más altos de impuesto global complementario. Menos de 5 por ciento de los que reciben dividendos están en los tramos sobre 35 por ciento. 
Gráfico 11. IMPUESTO SUSTITUTIVO FUT (ISFUT), RÉGIMEN TASA PROMEDIO (\%)

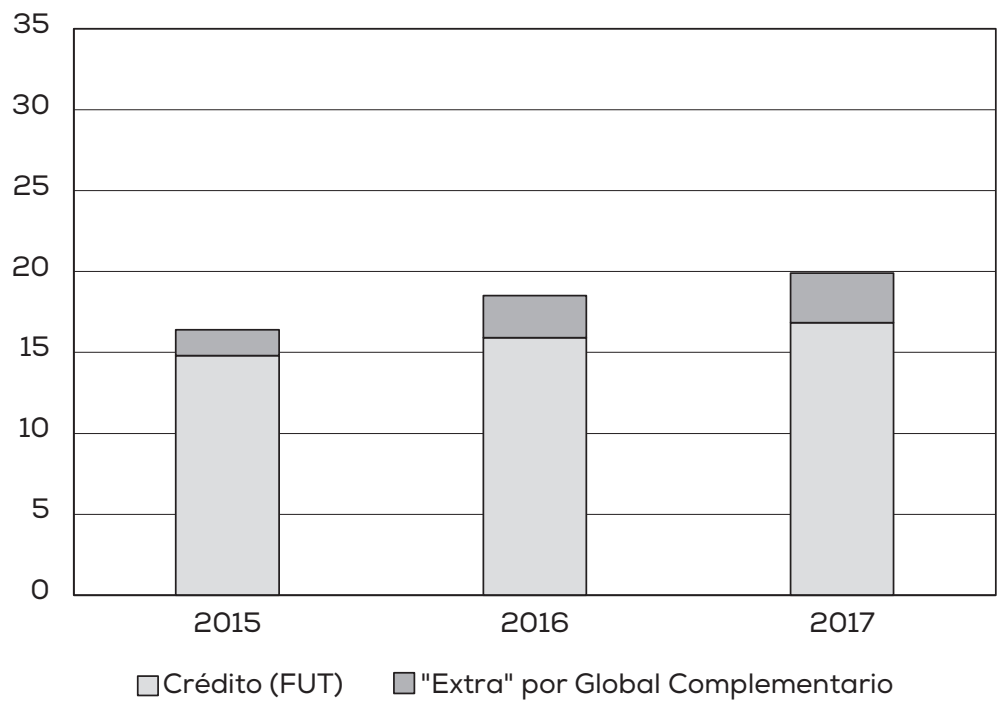

Fuente: Ministerio de Hacienda.

Gráfico 12. IMPUESTO SUSTITUTIVO FUT (ISFUT), RÉGIMEN 32 POR CIENTO (\%)

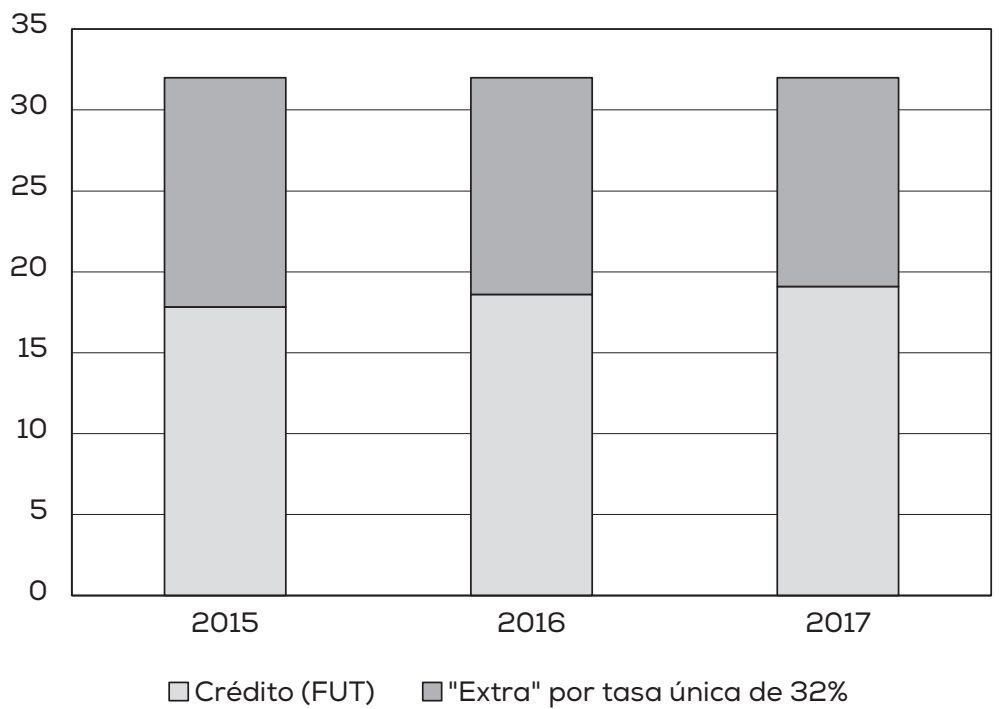

Fuente: Ministerio de Hacienda. 
¿Qué hacer con el sistema tributario durante los próximos años? Posiblemente, nada en el corto plazo: estamos terminando una transición compleja y lo razonable es evaluar en detalle el comportamiento del sistema antes de cambiarlo una vez más.

Hacia el mediano plazo, suponiendo que se quiere mantener la carga tributaria al nuevo nivel, surge una pregunta básica: ¿vale la pena volver a integrar el sistema? ¿Conviene simplemente desintegrarlo y de esa manera simplificarlo?

Para decidir lo anterior es necesario contestar seriamente la pregunta de si la posible distorsión que se evita con la integración, llamada "doble tributación", es tan relevante, y si un sistema desintegrado podría también atenuarla. Además, se debe abordar la importancia de que los ingresos del trabajo y del capital paguen, eventualmente, tasas distintas. A nivel teórico, la respuesta es clara: no existe ninguna ganancia importante al integrar.

Adicionalmente, la desintegración permitiría mantener los incentivos al ahorro dentro de la empresa y eliminar la manifiesta inequidad tributaria horizontal que existe actualmente cuando las rentas son de distinta fuente. Además, hay suficientes países que crecen a tasas altas y muchos se han desarrollado con un sistema desintegrado. ${ }^{11}$

Alternativamente, aunque es posible volver a un sistema integrado, parece difícil eliminar los mecanismos para eludir, por ejemplo, empleando esquemas que dividen los ingresos del capital entre distintos individuos que, desde el punto de vista económico, no son sus dueños. En términos de elusión, es particularmente dañina la facilidad de reinvertir en sociedades distintas a la que genera la utilidad.

Finalmente, respecto de nuevos incrementos en recaudación, es probable que las posibilidades se hayan agotado en el ámbito corporativo, tanto por los niveles alcanzados como por las tendencias que se aprecian a nivel global. De hecho, se debe evaluar seriamente la conveniencia de disminuir la tasa corporativa.

Hay, sin embargo, dos espacios a considerar, aunque ambos son políticamente difíciles. El primero a considerar es el impuesto al ingreso de las personas, especialmente aquéllas de clase media, así como

11 Obviamente, desintegrar implica también tener una tasa de impuesto especial a los dividendos que sea significativamente menor que la tasa del global complementario. Es la manera de evitar gravar al capital con tasas que pondrían severamente en riesgo la inversión. 
el mínimo exento. Comparado con cualquier país OCDE, en Chile la tasa de impuesto de un asalariado que gana 1,7 veces el salario promedio (cerca de un millón de pesos) es extremadamente baja (gráfico 13). Cabe notar que la OCDE considera la cotización de salud en Chile como un impuesto (lo que no hace en el caso de las pensiones), por lo que la tasa es marginalmente mayor a siete por ciento. El mínimo exento (relativo al ingreso medio), o el ingreso a partir del cual se comienza a pagar impuestos a las rentas, es por lejos el menor en la OCDE. ${ }^{12}$

Sucede algo similar si se compara a Chile con otros países OCDE en momentos cuando tenían nuestro PIB per cápita o uno menor (gráfico 14). No es casualidad entonces que en las comparaciones internacionales Chile figure entre los países con más bajo impuesto al ingreso personal (a esto se suma el que la renta del capital paga tasas bajas, como se discute más arriba). Por cierto, ésta es una reforma políticamente costosa, pero contribuiría a que el ciudadano promedio actúe bajo el concepto anglosajón de "tax-payer" y exija más eficiencia al Estado, e incluso tener un rol en el destino de sus impuestos.

La segunda fuente es el impuesto al valor agregado (IVA) a los servicios. Si bien Chile mantiene una buena disciplina al tener una tasa uniforme y ausencia de excepciones, el IVA sólo se aplica a los bienes. No parece haber buenas razones para que los servicios estén exentos. Es la práctica en muchos países y permitiría una recaudación significativamente mayor con costos bajos en distorsiones. En principio, todos los servicios deberían pagar este impuesto.

\subsection{La reforma laboral}

Aunque no era una de las llamadas "reformas estructurales" del programa de gobierno, los cambios al Código del Trabajo ganaron gran protagonismo en 2015 y se transformaron en un nuevo foco para la desconfianza empresarial luego de la reforma tributaria.

La lógica del proyecto original era simple: darles más poder a los sindicatos para negociar, incentivar la sindicalización y eliminar mecanismos que se estimaban como atentatorios para los derechos del trabajador. Se suponía que, con sindicatos más fuertes, se podría lograr

12 Para una comparación de distintos impuestos y estructuras, ver Rubio y Vergara 2017. 
Gráfico 13. OCDE TASA DE IMPUESTO PERSONAL PROMEDIO EN 2015 (\%)

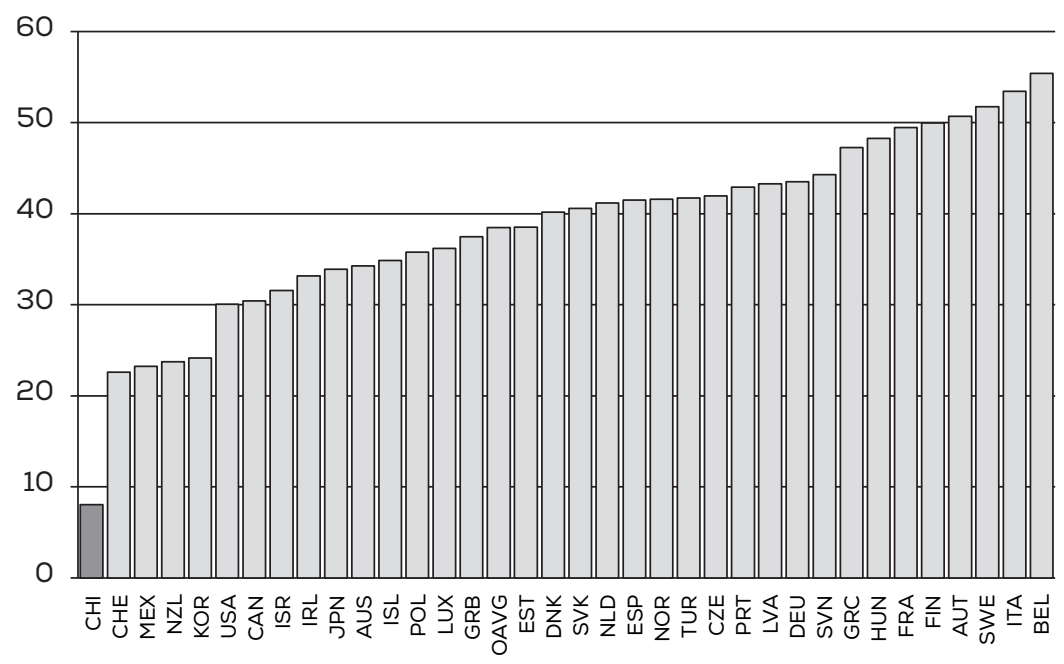

Para una persona soltera con salario igual a 1,7 veces el salario medio.

Fuente: OCDE.

Gráfico 14. TASA DE IMPUESTO PERSONAL PROMEDIO PAÍSES PIB PC $\leq$ CHILE (\%)

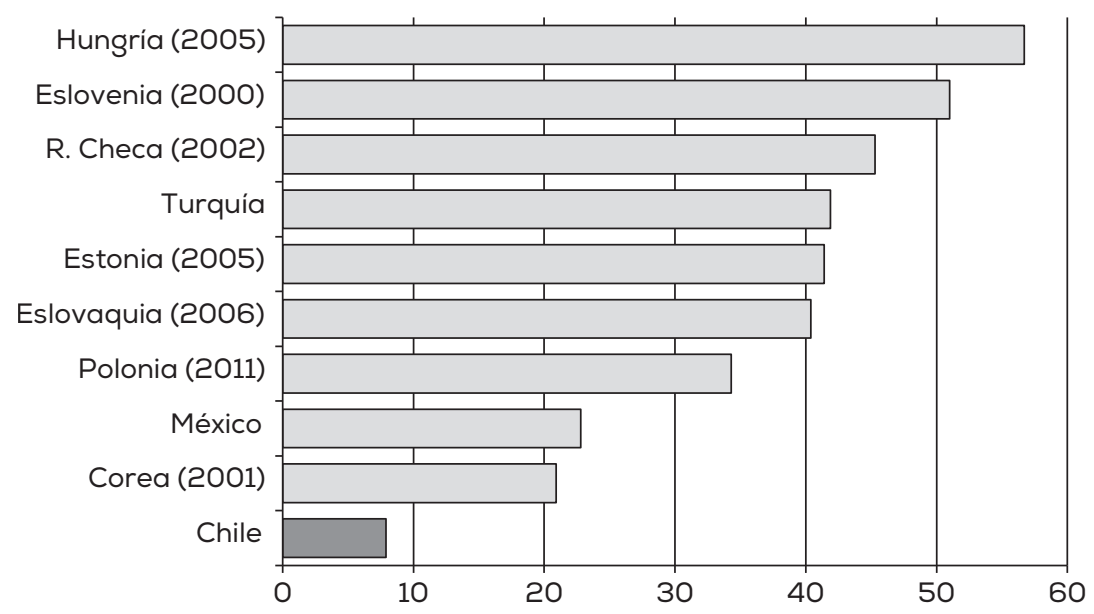

Para una persona soltera con salario igual a 1,7 veces el salario medio.

Fuente: OCDE. 
una mejor distribución del ingreso y, posiblemente, más paz social. Para mantener los costos de una huelga dentro de márgenes razonables, el proyecto daba a los servicios mínimos un rol preponderante e intentaba desincentivar actos de fuerza como las tomas de los accesos a las empresas por parte de los huelguistas.

Es importante reconocer que la regulación laboral es una política pública en la que fácilmente chocan objetivos de eficiencia y productividad con los de equidad. ${ }^{13} \mathrm{Si}$ el mercado laboral fuese uno cualquiera, no existirían contratos detallados, normativa sobre vacaciones, horas máximas de trabajo, etcétera. Pero este tipo de regulaciones existen desde hace décadas y en casi todas las economías, por buenas razones. También es un área con enfoques multidisciplinarios que no siempre conversan en armonía. Por ejemplo, hay enfoques legales que chocan con principios de la economía, lo que dificulta la construcción de acuerdos.

Éste es también un ámbito en que los efectos de equilibrio parcial y estáticos pueden ser muy distintos a los de equilibrio general y dinámicos; es decir, donde los efectos indirectos y los que suceden con el paso del tiempo pueden ser opuestos a los que se buscan. ${ }^{14}$ En general, se trata de realidades que al mundo político le cuesta entender o prefiere no entender.

Esta reforma fue altamente compleja desde el punto de vista de su tramitación y resultados. Hacia abril de 2015, antes del cambio de gabinete, el gobierno ya había pactado varios contenidos con la Central Unitaria de Trabajadores (CUT) y el debate había avanzado más allá del programa de gobierno. A esa altura había interpretaciones bastante ambiguas y fronteras poco claras respecto de lo que se entendía por reemplazo de trabajadores en huelga, titularidad sindical, piso de negociación y pactos de adaptabilidad.

Luego de que se eliminara la negociación por ramas y el piso indexado al IPC - incluyendo bonos y otros beneficios - en la negociación colectiva, materias que se habían incluido en la Comisión de Tra-

${ }^{13}$ En la conferencia anual del Banco Central de 2004 sobre mercado laboral, se presentaron dos trabajos empíricos que mostraban estos dilemas: Calderón et al. (2007), para crecimiento, y Calderón et al. (2005), para distribución del ingreso.

${ }^{14}$ Por ejemplo, dificultar fuertemente el despido hace que la cantidad de despidos caiga en el corto plazo, pero que la contratación también lo haga y aumente la mecanización de los procesos, dejando eventualmente en peor condición a los trabajadores. 
bajo de la Cámara de Diputados, el proyecto ingresó al Senado, donde se inició un largo camino de tiras y aflojas. Si la reforma tributaria era algo técnico, casi impenetrable para el mundo político y que más bien se discutía entre expertos, la laboral era todo lo contrario: la gran mayoría de los parlamentarios de gobierno tenía opiniones fuertes, forjadas durante años e influidas por los movimientos sindicales. Por el lado de los gremios empresariales y la oposición, la carga ideológica era exactamente la opuesta e igual de fuerte.

Las pymes jugaron su propio partido y lograron una serie de tratamientos diferenciados respecto de las empresas más grandes. En el debate, también se lograron otros avances para todo tipo de empresas, como aquellos mecanismos destinados a balancear el proceso de huelga: posibilidad de descuelgue, que el empleador entregara nuevas ofertas que se votarían en urnas y bajo voto secreto, y algunos elementos contra el comportamiento violento. También fue importante limitar algunas prácticas abusivas (como el sindicato del día después) y reglar mejor el proceso de determinación de servicios mínimos, aunque la práctica ha mostrado que queda aún espacio para acotar la discrecionalidad de la Dirección del Trabajo en este ámbito.

El proyecto aprobado les entregó a los sindicatos la posibilidad de vetar la extensión de beneficios logrados en la negociación a trabajadores no sindicalizados (para incentivar la sindicalización y reducir el free rider, como se conoce el hecho de recibir beneficios sin contraprestación alguna), la posibilidad de que el sindicato y el empleador celebren distintos pactos para adaptar la jornada laboral a necesidades específicas y, por último, la titularidad sindical; es decir, la prohibición de que otros grupos negociadores pudieran acordar un contrato colectivo cuando exista un sindicato.

Lo más complejo fue abordar los límites al reemplazo de un trabajador en huelga, lo que fue fuertemente resistido por la mayoría de la coalición de gobierno. La redacción final prohíbe el reemplazo, pero al mismo tiempo permite al empleador efectuar las "adecuaciones necesarias" para que los trabajadores no involucrados en la huelga pudieran ejecutar las funciones convenidas en sus contratos de trabajo. De este modo, se protege la libertad de los trabajadores que no están en huelga e indirectamente se acotan las cuasi rentas que podría extraer una huelga. 
Pero la reforma no terminó ahí. La oposición recurrió al Tribunal Constitucional (TC) y éste eliminó la titularidad sindical y algunos elementos secundarios. La Presidenta decidió enviar un veto supresivo para eliminar todos los pactos de adaptabilidad, excepto uno sobre responsabilidades familiares.

Es imposible evaluar hoy los efectos de la reforma laboral porque ellos se verán sólo con el paso del tiempo. Se comenzó a aplicar recién el 1 de abril de 2017 y, si bien se ha observado una disminución en el número de huelgas, existió evidencia de adelantamiento de negociaciones para que se rigieran por la normativa previa a la nueva ley. Cabe destacar, también, que la huelga más costosa de los últimos años, en términos de producción, la de minera BHP, se realizó a comienzos de 2017, bajo las anteriores reglas.

La ley final dejó a todos los actores con algún grado de descontento, lo que sugiere que tuvo cierto equilibrio. Al mundo privado le preocupó el mayor poder de los sindicatos y algunas rigideces que subirán los costos laborales. La CUT quedó insatisfecha porque no obtuvo la titularidad sindical y el reemplazo interno en caso de huelga no quedó completamente cerrado. Desde el punto de vista de la eficiencia del mercado laboral, es costoso no tener la posibilidad de un reemplazo interno mejor reglado y tampoco pactos de adaptabilidad.

El temor que produjo y aún produce la reforma laboral en aquellos que toman decisiones de contratación es un aspecto que debe ser monitoreado. Por ahora, no hay evidencia de una dislocación de la demanda por trabajo. Se apreció más contratación que la que sugiere el ciclo económico, aunque su composición levanta dudas. Algunos cambios que produjo la reforma, como la prohibición del reemplazo, tenían un uso limitado, pero ello no significa que no tuvieran efectos. De hecho, la mera posibilidad de reemplazo interno y externo moderaba el riesgo de que la parte empleadora tuviera que pagar montos excesivos en una negociación. Desde una perspectiva ex ante, este riesgo tiene efectos en inversión y contratación.

Pero hay que considerar también que fallos sucesivos de los tribunales de justicia sobre casos laborales, con decisiones pro trabajadores, tanto en el ámbito privado como público, ya habían modificado ciertas prácticas hasta ahora aceptadas, por lo que los cambios de la reforma son menos intensos que lo que un primer análisis sugiere. 
¿Qué hacer hacia adelante? No es fácil que el sistema político pueda concordar un mejor equilibrio; por ejemplo, uno con sindicatos empoderados y capaces de internalizar en sus decisiones una perspectiva de largo plazo y los efectos en la empresa, como en el caso de Alemania. O uno que expanda más claramente las posibilidades de reemplazo interno, que el análisis económico sugiere es necesario para delimitar el poder de negociación de la parte trabajadora, de manera que una huelga tenga efectos relevantes, pero, al mismo tiempo, no permita una apropiación indebida de cuasi rentas (y, a partir de la proyección de esta situación por parte de la parte empresarial, lleve a menos contratación).

En esta discusión, no se debe olvidar que ayudar a trabajadores protegidos se hace en buena parte a costa de los no protegidos, que en la mayoría de los casos no existen grandes rentas que pueden redistribuirse, y que despreciar los efectos en los incentivos puede empeorar la situación para los trabajadores más vulnerables. Del mismo modo, se deben dar pasos para generar mayor confianza y sinergia entre los actores sociales en cada empresa y a nivel general, superando las agendas ideológicas que marcan las visiones de las partes y las desconfianzas que existen tanto hacia los objetivos como hacia la capacidad de los dirigentes sindicales o de sus contrapartes empresariales.

Es importante revisar si la determinación de servicios mínimos funciona adecuadamente. Es uno de los pilares de la reforma: delimitar el poder de negociación de las partes de manera de cautelar un equilibrio apropiado (como lo era el reemplazo externo anteriormente). Hasta ahora, los procesos han generado bastante controversia y pocas reglas de utilidad.

Con la decisión del TC, los grupos negociadores quedaron en un vacío legal, con riesgo de judicialización. Una posible solución es hacer un cambio constitucional para tener titularidad a cambio de, por ejemplo, pactos de adaptabilidad amplios, ojalá con menos limitaciones que las que imponía el proyecto aprobado. Alternativamente, se puede legislar sobre grupos, pero probablemente esto es políticamente inviable.

Queda, por último, tratar de mantener los pocos espacios de ajuste de salarios para hacer frente a los distintos shocks y buscar maneras para que los nuevos trabajadores, que requieren jornadas flexibles, puedan encontrarlas. 


\subsection{Las reformas a la educación}

Desde el punto de vista fiscal, el grupo de reformas a la educación fue por lejos el que ocupó más recursos. Como ya se mencionó, el conjunto de reformas podría costar 3,2 por ciento del PIB si se incluyera la gratuidad universal. Dependiendo del destino de las reformas en la educación superior, el gasto incremental en régimen comprometido en comparación a 2014 varía entre 1,6 y 2 por ciento del PIB.

Las reformas (y leyes auxiliares) tuvieron como objetivo avanzar hacia garantizar el acceso a una educación de calidad en todos los establecimientos educacionales del país, en los tres niveles educativos. Gracias al nivel de desarrollo obtenido previamente por Chile en materia educacional, se buscó ampliar la cobertura en educación parvularia y superior en lugares donde se consideraban necesarias; consolidar un Sistema de Aseguramiento de la Calidad y el desarrollo de nuevos marcos regulatorios para cada nivel educativo; y la especialización y profesionalización de la gestión educativa y de quienes trabajan en el sistema educativo en los niveles parvulario y escolar.

Para esto se modificaron cinco grandes áreas, que incluyeron: (i) instalación del Sistema de Aseguramiento de la Calidad y una ampliación significativa de cupos en educación parvularia (salas cunas y jardines infantiles); (ii) cambios regulatorios profundos y de financiamiento en la educación escolar subvencionada; ${ }^{15}$ (iii) el establecimiento de una Política Nacional Docente, la que incluyó un carrera docente para profesores de establecimientos públicos y particular subvencionados, con mejores sueldos y evaluación; (iv) el cambio de administración del sistema escolar estatal desde el nivel municipal a 70 servicios especializados, y (v) una reforma regulatoria y de financiamiento de la educación superior con mejoras al Sistema de Aseguramiento de la Calidad.

Aunque habitualmente se piensa que el mayor gasto realizado ha sido en educación superior, en los hechos, dada la secuencia de proyectos, se han concentrado más recursos para la etapa escolar y parvularia. Del 0,8 por ciento del PIB de gasto incremental a 2017, un tercio se ha destinado a educación superior y el resto, a los demás segmentos.

${ }^{15}$ Como referencia, en 2016, el 56 por ciento de los escolares estaba en colegios particulares subvencionados; el 36 por ciento, en municipalizados, y el 8 por ciento, en particulares pagados. 
Los cambios en educación parvularia incluyeron la creación de una subsecretaría especializada para este sector en 2015 y un significativo avance en infraestructura y en personal para atender la expansión de la matrícula en este nivel. La cobertura aumentará desde 23 a 30 por ciento entre 2014 y 2018, lo que significa 70.100 nuevos cupos de un total de 226.000. El número es menor que el inicialmente previsto en el programa (124.000), principalmente debido a restricciones de ejecución $\mathrm{y}$ de financiamiento.

De las cinco áreas mencionadas, sólo las modificaciones regulatorias a la educación particular subvencionada fueron aprobadas sin el concurso de la oposición. Este proyecto se despachó a comienzos de 2015, antes del cambio de gabinete y de los cambios de composición del TC. Incluyó tres transformaciones profundas que buscaron reducir la alta segregación del sistema escolar: se congeló el copago que podían cobrar los establecimientos subvencionados, el que gradualmente desaparecerá al ser reemplazado por recursos públicos; se sustituyó la selección de alumnos que pueden hacer los colegios por un sistema de asignación según preferencias de la familia y sorteo en caso de exceso de demanda, y se estableció que para participar del sistema los colegios no podían tener fines de lucro. Estos cambios acercan nuestro sistema a lo que es más habitual en otros países. ${ }^{16}$

Esta ley enfrentó varios problemas y críticas. El haber partido por transformaciones para mejorar la educación subvencionada en vez de la estatal ha sido motivo de repetidos debates. El argumento principal para la secuencia escogida fue lo que los economistas llaman "equilibrio general": era difícil avanzar en la parte estatal si la subvencionada mantenía espacios de ventaja que impedían una real integración y competencia con la primera. El argumento contrario ha sido que había que comenzar por mejorar la educación estatal para limitar su disminución en importancia relativa.

Se debe admitir también cierto carácter contracultural del fin de la selección y del copago, que las familias percibían como una vía para aportar a la educación de sus hijos y acceder a calidad, y separarse de otros niños de menor capital social. Es, sin embargo, un costo que valdría la pena pagar si se busca de verdad un sistema de educación integrado.

${ }^{16}$ Ver Epple et al. (2015), para una descripción del sistema de charter schools de EE.UU. 
También fue compleja la transformación de los colegios en instituciones sin fines de lucro. Por un sesgo ideológico en la izquierda, fue posible legislar sólo a fines de 2017 para que las instituciones puedan pagar un arriendo regulado a perpetuidad por su infraestructura. Las soluciones iniciales basadas en una autocompra a través del sistema financiero (con garantías estatales) o una autocompra directa habían enfrentado dificultades de operación.

Las leyes para la creación de un Nuevo Sistema de Educación Pública (que incluye la desmunicipalización) y de la Política Nacional Docente se aprobaron en acuerdo con la oposición y ambas requieren de una evaluación futura y posiblemente de refinamientos. Las dos constituyen pasos cruciales para mejorar la educación: en un caso, atrayendo talento hacia la pedagogía gracias a mejores salarios, premios por desempeño y una formación más exigente en las universidades; en el otro, mejorando la administración de las salas cunas, jardines infantiles y los colegios municipalizados, que en una gran mayoría es deficiente, no tiene la escala o los profesionales apropiados ni los incentivos adecuados.

En el caso de la carrera docente, se aprobó por primera vez un beneficio contingente al crecimiento del PIB. Específicamente, se ampliarían las horas no lectivas por encima de un aumento mínimo, dependiendo de si el crecimiento económico en los años previos estaba por encima de un umbral. Fue un cambio útil que inició la discusión sobre los factores desencadenantes (que llamamos "gatillos") para avances en gratuidad.

Por último, la reforma de la educación superior, que se separó en un proyecto general para este nivel educativo y otro específico para las universidades estatales, incluye cambios regulatorios significativos que consideran una nueva superintendencia, modificaciones a la Agencia de Calidad y la obligación de acreditación para los establecimientos. También avanza en gratuidad y mayor financiamiento basal, y moderniza el tratamiento regulatorio a las universidades estatales y les entrega un apoyo financiero especial transitorio. ${ }^{17}$

${ }^{17}$ En educación superior también se crearon dos universidades y quince CFT estatales, se avanzó en modernizar la educación técnica para mejorar su pertinencia y empleabilidad, y se lanzó el programa PACE para que jóvenes especialmente capaces pero vulnerables pudieran acceder a la universidad. 
Como se discutió en la sección fiscal, los costos de la gratuidad son significativos, al totalizar aproximadamente 1,6 por ciento del PIB, y crecientes en cobertura. De ahí el diseño de gatillos para su avance gradual y contingente a los ingresos fiscales. El costo del avance depende crucialmente de cuántas instituciones adscriben y es creciente en deciles porque un mayor porcentaje de los menos vulnerables estudian en instituciones y eligen carreras más caras (además de que los deciles más vulnerables tienen sistemas de ayuda que son sustituidos por la gratuidad). Por ejemplo, pasar desde el estatus actual (2018) a una cobertura completa de instituciones para los seis primeros deciles prácticamente triplica el gasto. Pasar desde una cobertura de los nueve primeros deciles con todas las instituciones adscritas a una cobertura universal de estudiantes representa un gasto incremental de 20 por ciento (ver "Informe de finanzas públicas 2018").

Hay un sinnúmero de aristas en la reforma de educación superior que deben ser objeto de reflexiones y análisis por su importancia para el diseño de las políticas públicas. Una es (o fue) la madre de las discusiones: la necesidad o no de la gratuidad, ya sea de forma focalizada o universal. Los argumentos principales a favor y en contra son conocidos. Por un lado, reconoce la educación como un derecho, permite que nadie quede excluido si es capaz y trata a todos por igual. Por otro, dado que los que van a la universidad tienen importantes mejoras de ingreso, ellos deberían pagar por su educación en el momento de obtenerla o en el futuro si no se quiere desfocalizar el gasto público.

Sin embargo, el apoyo casi unánime en el Congreso del avance en gratuidad en 2018 para estudiantes que pertenecen al 60 por ciento más vulnerable, junto al establecimiento por ley del avance de la gratuidad de acuerdo al sistema de gatillos, ha generado una nueva realidad que supera esa discusión. ${ }^{18}$ Parece imposible que se retrotraiga la gratuidad y es muy improbable que se expanda rápidamente a la universalidad. Lo probable es que lleguemos al 70 por ciento en varios años más, considerando que los ingresos estructurales deben aumentar de manera persistente aproximadamente 1,5 por ciento del PIB para que se gatille ese avance.

${ }^{18}$ A esto se suma el que el nuevo gobierno electo sorpresivamente haya incorporado avances en gratuidad dentro de su programa actualizado para la segunda ronda presidencial. 
Una segunda arista, ligada a la gratuidad y su diseño, se refiere a la microeconomía e incentivos, especialmente considerando el sistema de colegiatura cara y heterogénea que existe en Chile. Con gratuidad se pierden las señales de precio, hay riesgos de sobreuso y la transición requiere de un cambio de financiamiento hacia formas basales, lo que despierta una puja enorme entre instituciones. Para funcionar, se requiere de un sistema que mantenga controlado el número de estudiantes matriculados, que costee de manera adecuada distintas carreras y movilice compensaciones hacia las universidades que las necesitan dado el control de la colegiatura. También hay que evaluar que no exista filtración. Hoy, las cifras de alumnos en gratuidad no permiten descartar que algunos que pertenecen a deciles superiores estén recibiendo el beneficio. Queda, por lo tanto, mucho por afinar desde el punto de vista institucional y de implementación para que el sistema funcione adecuadamente.

Un tercer aspecto, es que, con alta probabilidad y por un tiempo prolongado, existirá un número relevante de estudiantes que estará en instituciones que no adscribirán a la gratuidad (tanto por razones de principio como porque no pueden acomodar colegiaturas menores). Para estas entidades y para aquellos estudiantes que por su situación socioeconómica no se benefician de la gratuidad es importante rediseñar el Crédito con Aval del Estado (CAE).

Este nuevo diseño debe llevar el sistema de cobro desde los bancos al Estado, idealmente con la fuerza que se cobran los impuestos. También debe solucionar los casos respecto de los cuales la reducción de la tasas de interés no se ha podido aplicar o las personas no han tenido ingresos suficientes para pagar y se ha producido un aumento desmedido de su deuda. Pero a la vez es deseable que el nuevo crédito tenga no sólo una cuota contingente al ingreso (como se discute habitualmente), sino que a la tasa de interés. Esto permite que los más exitosos entre los futuros profesionales devuelvan el costo económico del crédito y, si se diseña apropiadamente, que el saldo insoluto nunca crezca. Se consigue, de esta manera, un sistema que tiene similitudes al impuesto a los graduados, pero con mejores incentivos. Por ejemplo, el pago en el impuesto a los graduados es ciego respecto de cuánto haya sido el gasto efectivo en educación, lo que incentiva el sobreuso.

Es también importante considerar que será necesario aumentar el monto de los créditos, si se quiere evitar el endeudamiento con el sis- 
tema privado. Pero para esto es conveniente diseñar mecanismos que eviten que aumentos del crédito gatillen alzas del copago. Aunque es posible que la competencia se haga cargo de este problema, la evidencia internacional al respecto no es tranquilizadora. Un posible diseño es aumentar el crédito máximo sobre los aranceles regulados y, al mismo tiempo, hacer más estricto el esquema de garantías por parte de la institución de educación para este crédito adicional.

Finalmente, entrego una reflexión que se aplica a la gratuidad universitaria ( $\mathrm{y}$, parcialmente, a la educación subvencionada). Es sabido que el gasto total en educación en Chile es similar al promedio de los países de la OCDE, en torno al 5,5 por ciento del PIB. Sin embargo, antes de las reformas, este gasto tenía un componente privado muy alto, del orden de un tercio, en buena parte por lo que sucede en educación subvencionada y superior (donde dos tercios es gasto privado). ${ }^{19}$ Cambiar esta combinación es un paso importante por diversos motivos, pero hay que considerar que el avance en gratuidad, especialmente en educación superior, no asigna necesariamente más recursos netos a la educación, sino que, básicamente, sustituye recursos que eran de cargo de las familias. Dado que Chile tiene una matrícula terciaria bruta relativamente alta y una estructura poblacional más joven que el típico país OCDE, es importante redireccionar esfuerzos para allegar más recursos a la educación y no meramente sustituirlos.

\section{CRECIMIENTO (Y DESEMPLEO)}

El crecimiento económico fue un ámbito en que los resultados estuvieron muy por debajo de las expectativas, aunque en comparación con el desempeño de otros países relevantes tampoco pueden calificarse como negativos. Fue particularmente difícil encontrar instrumentos que ayudaran a una reactivación más palpable y, cuando existían, no era fácil ejecutarlos por restricciones de distinto tipo. En contraposición, en parte gracias a una estrategia de contención salarial y a la propia expansión del gasto fiscal, el desempleo se mantuvo por debajo de sus promedios históricos y muy contenido en comparación con otros períodos de desaceleración.

19 Ver Galleguillos et al. (2016), para comparaciones y una descripción de la asignación de dineros públicos en la educación superior. 


\subsection{Diagnósticos}

A nivel de economistas no existía (ni parece aún existir) un diagnóstico compartido sobre la importancia de los factores detrás de la desaceleración y, por lo tanto, de la reacción de política más adecuada. Para cualquier observador, era evidente que no había desequilibrios macroeconómicos significativos que frenaran el crecimiento. Y si bien era obvio que Chile estaba absorbiendo un shock externo relevante y que la agenda de reformas tenía ciertos efectos contractivos de corto o largo plazo, definir cuánto era el efecto de cada uno de estos factores y las implicancias de política se transformó en una discusión sin fin y con bastante ideología.

Para muchos economistas, una parte sustancial de la desaceleración (que incluso llevó a algunos a predecir una recesión) era autoinfligida por la agenda de reformas. Éstas, se argumentaba, tenían efectos directos en incentivos y distorsiones, e indirectos en confianza y expectativas, que tumbaron la economía. La implicancia era evidente: abandonar esta agenda, deshacer lo más posible las reformas, tratar de apegarnos al statu quo.

Para otros, Chile vivía un proceso de ajuste a un shock externo intenso, cuyas consecuencias fueron mucho mayores y más duraderas a las esperadas. El precio del cobre en particular, pero también la situación de la región generaban impactos adversos de primer orden. Se necesitaba una política macro algo más estimuladora, una depreciación relevante del peso, coordinación fina con el Banco Central y bastante paciencia. $^{20}$

La discusión giró inicialmente en banda sin mucha evidencia y desde la trinchera política. Por ejemplo, se culpaba a las reformas de toda disminución de la actividad económica y se exageraba la interpretación de estimaciones empíricas de terceros. ${ }^{21} \mathrm{O}$ se apuntaba a las en-

${ }^{20}$ Cabe notar que esta misma receta se debía aplicar si el shock principal era uno de confianza, que es eminentemente un shock de demanda. Muy pocos proponían esto.

${ }^{21}$ Por ejemplo, el capítulo especial del World Economic Outlook (WEO) del FMI de octubre de 2015, que estudia los efectos macroeconómicos de cambios en los precios de las materias primas en los países que los producen. La discusión no consideraba que las estimaciones entregan un efecto muy persistente, mayor para caídas de precio, y que era válido concluir que se podían explicar entre cero y tres puntos de caída de actividad en Chile cuando se consideran los rangos estadísticos de las estimaciones. 
cuestas de expectativas como prueba de un problema de confianza, sin reconocer su evidente endogeneidad al ciclo.

Un esfuerzo más serio fue la construcción de un índice de incertidumbre a partir de contar palabras clave en los medios, cuestión que se ha hecho en diversos países y que muestra alguna correlación adelantada con el ciclo (Cerda et al. 2016). El Banco Central también participó en el debate, deduciendo de algunos ejercicios empíricos que existía un "shock autónomo" en el comportamiento de la inversión, una manera elegante de decir que había un problema de confianza relevante. Ambos ejercicios fueron útiles en mostrar que las reformas estaban lejos de ser inocuas, aunque no eran concluyentes respecto de que fueran el factor principal tras la desaceleración.

La carga política detrás de esta discusión aumentó durante 2016, cuando la inflación cedió y se comenzó a discutir la conveniencia de una política monetaria más estimulativa. El nuevo argumento era que bajar las tasas no tendría efectos en la actividad porque lo que enfrentaba Chile era "un problema de expectativas", lo que implicaba que ahora un problema de confianza modificaba elasticidades, no sólo el nivel de inversión deseada.

La evaluación interna en Hacienda era que ambos factores incidían, pero con una relevancia mayor del shock externo. Si había que explicar unos 3 puntos porcentuales de menor crecimiento, en torno a uno era posiblemente a causa de distintos efectos de las reformas, muchos de los cuales eran transitorios.

Tres elementos fueron centrales para esa convicción. Primero, si se comparaba la disminución del crecimiento del PIB no minero chileno con el de otros países de alto crecimiento de la región, como Colombia y Perú, había muy pocas diferencias.

Segundo, la caída en la inversión minera había sido inesperadamente profunda, mientras que la no minera aumentó tímidamente estos años (gráficos 15 y 16). La parte minera llegó a representar un tercio del total en 2013, y tuvo una caída de 40 por ciento acumulada a 2016 (y otro tanto en 2017). La magnitud de estos cambios implica que el boom y bust mineros explicaban buena parte del ciclo 2010-2017.

Y tercero, si se comparaba la evolución de la inversión en capital fijo desde 2011 hasta 2016 en Australia, Chile, Canadá y Perú (todos países mineros), las cifras eran prácticamente indistinguibles. Incluso, 
Gráfico 15. FORMACIÓN BRUTA DE CAPITAL FIJO EN SECTOR MINERÍA (\% PIB)

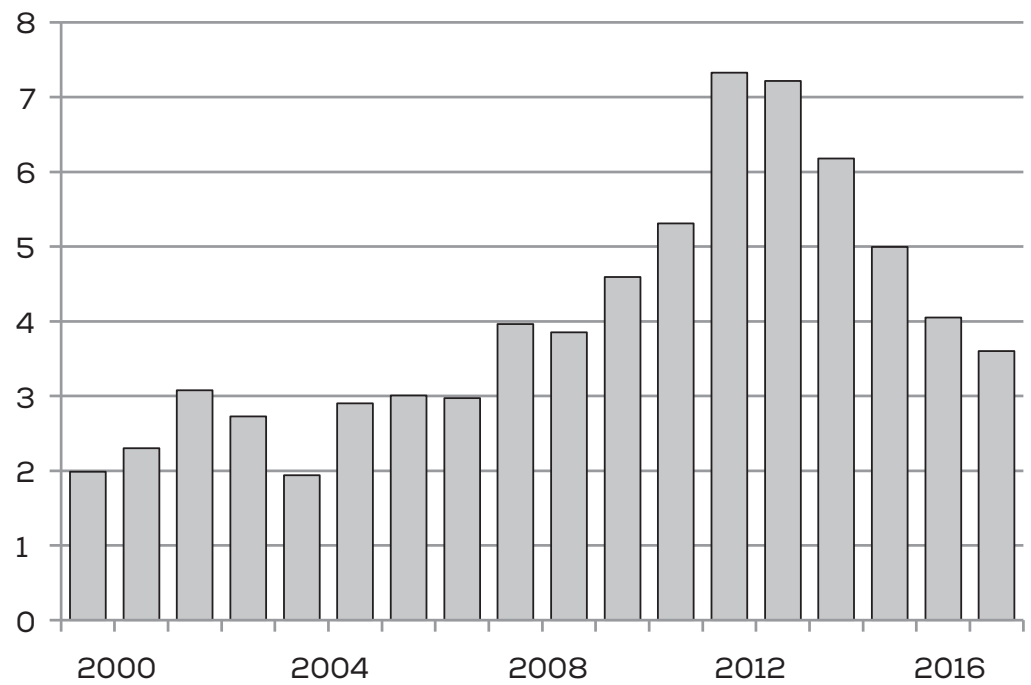

Fuente: Banco Central de Chile. Para 2016 se usan las proyecciones del IPoM de diciembre de 2017.

Gráfico 16. FORMACIÓN BRUTA DE CAPITAL FIJO EN SECTORES DISTINTOS A MINERÍA (\% PIB)

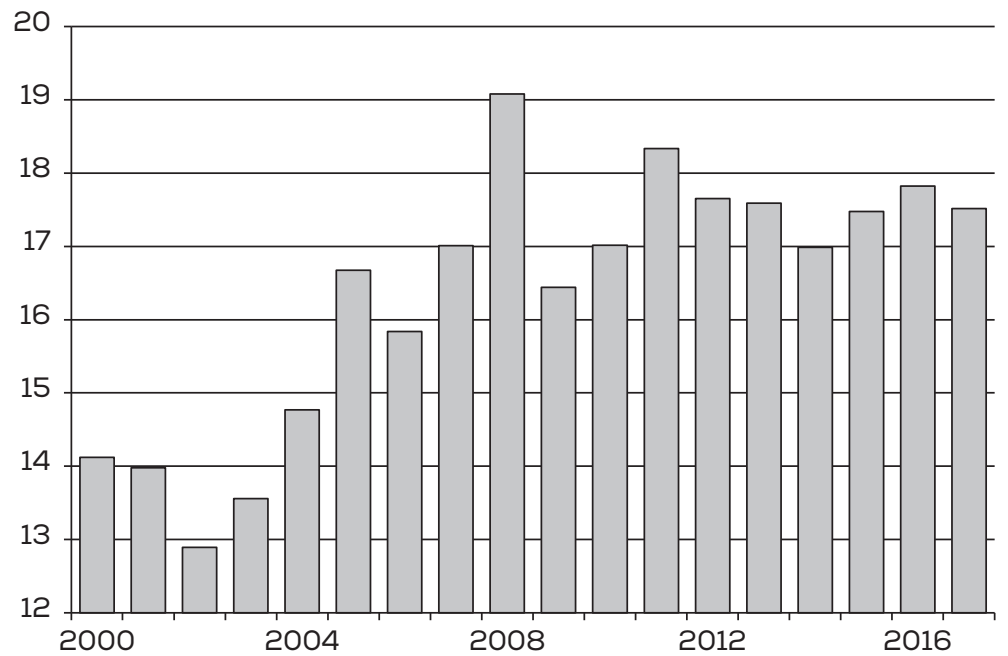

Fuente: Banco Central de Chile. Para 2016 se usan las proyecciones del IPoM de diciembre de 2017. 
la caída acumulada de Chile en 2014-2016, que tanto llamó la atención a nivel local como algo inédito, fue la menor entre estos cuatro países. ${ }^{22}$

Para enfrentar el shock externo había un número de instrumentos relativamente limitado y bien conocido. De partida, la política fiscal basada en una regla estructural es básicamente neutral y deja al Banco Central como el encargado de modular el ciclo (en la medida en que la inflación lo permita). Si además la política fiscal se empeña en una consolidación estructural gradual, mayor razón para una política monetaria acomodaticia. Durante 2016-17 se implementó una política monetaria expansiva y hubo un aumento relevante del tipo de cambio real, aunque no es claro qué pensaba el Banco Central respecto del rol de los distintos shocks y el rol del instrumental monetario.

Del lado fiscal, y con el presupuesto amarrado por la regla, los esfuerzos se concentraron en la capitalización de las empresas públicas, fuera con montos extraordinarios o retiros limitados de utilidades, en la medida en que avanzaban en sus planes de inversión. Con esto, además de impulsar directamente el gasto en inversión, se incentivaba a las administraciones respectivas a ejecutar los planes a tiempo.

También se logró, aunque con bastante lentitud inicial, expandir la cartera de concesiones. En 2017 incluso se agregaron algunos embalses, además de la cartera habitual de carreteras urbanas e interurbanas y de aeropuertos. Fue imposible reimpulsar las concesiones de hospitales, en parte por temor a la reacción de los gremios del sector salud.

En el lado financiero, las tasas de interés de largo plazo eran bajas y no se enfrentaron episodios de iliquidez que requirieran acciones $a d$ hoc. Eso sí, la Corfo y el BancoEstado (en este caso, vía Fogape) continuaron otorgando garantías para facilitar el acceso a financiamiento a pequeñas y medianas empresas.

22 Una pregunta evidente es por qué, entonces, estos tres países tuvieron una desaceleración del PIB menor que la de Chile durante estos años. Una razón poderosa es que el volumen de exportaciones (de bienes y servicios) tuvo un comportamiento muy diferente. Mientras que en Chile el volumen exportado cayó 0,5 por ciento promedio anual en 2014-2016, en Perú creció 4,4 por ciento (debido a una mayor producción de cobre gracias a que el boom de inversión previa expandió capacidad), y en Australia y Canadá lo hicieron con 6,7 y 3,4 por ciento, respectivamente (por factores tales como un mayor crecimiento de socios comerciales y una política monetaria más agresiva que se reflejó en un tipo de cambio más competitivo). 
También se profundizaron los esfuerzos para integrar el mercado de bonos local con el exterior y así mejorar su liquidez. Pasos importantes en esta dirección fueron la incorporación de Chile a las plataformas de pagos internacionales, algunas simplificaciones impositivas para los impuestos a los intereses, y las primeras emisiones conjuntas en Chile y en el exterior en moneda local y jurisdicción chilena.

Respecto de las reformas, se buscó atenuar el efecto de algunas de las distorsiones y, especialmente, acotar el miedo y desconfianza que producían. La estrategia inicial fue "ponerles orillas" a las distintas reformas; esto es, encapsularlas dentro de algo predecible. Y luego afinarlas dentro de lo políticamente posible.

En la misma línea, se buscó incorporar más racionalidad económica a algunas reformas (tributaria, laboral, educacional y descentralización); así como modular, moderar e incluso postergar ciertos proyectos con claro impacto en la economía (Código de Aguas, Sernac, Ley de Pesca, glaciares, la llamada agenda laboral oculta, la Ley de Isapres y la Ley de Sanitarias, entre otros). También se impulsaron algunas nuevas iniciativas que podían apuntalar la confianza y tener efectos positivos en inversión, como la adscripción al Trans-Pacific Partnership (TPP) - a pesar del disgusto de parte de la coalición- y la aprobación de varias iniciativas relacionadas con la productividad.

También fue importante apoyar la agenda en energía y algunos megaproyectos específicos. Se concretaron cambios regulatorios que mejoraron la competencia en este ámbito, los que, junto con la disminución del precio del petróleo y con desarrollos tecnológicos que hicieron más eficientes las energías renovables no convencionales, permitieron una reducción sustancial de los precios de la electricidad. La licitación de 2017 resultó en un precio — nominal— 75 por ciento inferior al de 2012.

Por otra parte, la maraña de permisos y burocracia que debe sortear un proyecto de inversión de gran tamaño en Chile ha crecido y se ha tornado menos predecible. Para ayudar a movilizar la inversión pública y privada formamos un equipo "destrabador" instalado en el Ministerio de Economía, que ayudó a disminuir tiempos de tramitación, apoyando algunos procesos y coordinando a distintos actores; todo esto, sin saltarse pasos y con pleno apego a la institucionalidad ambiental.

Dentro de la estrategia económica, hubo también un esfuerzo por cambiar el tono de la interacción con el sector privado. Era evidente que había diferencia de visiones sobre las reformas entre el gobierno y 
los empresarios, y que asuntos como los casos de colusión, el financiamiento irregular de la política y el discurso antilucro que se inició en la reforma de la educación habían introducido nuevas tensiones. Más que tratar de convencerlos, los invitamos a trabajar en aquellos temas de la agenda en que podíamos construir acuerdos, sin que los disensos en otras áreas nos impidieran interactuar.

La agenda de probidad y transparencia, los temas de energía y los relacionados con mejorar la productividad, entre otros, fueron espacios para avanzar en temas de interés común. Esto fue complementado por diversas intervenciones destinadas a valorar el rol de los mercados competitivos, la propiedad privada y la predictibilidad de las reglas del juego, factores que contribuyen al crecimiento económico. ${ }^{23}$ Esto también abarcó la discusión sobre pensiones, donde se buscó mantener un tono lo más objetivo posible respecto del rol que cumplen las AFP.

\subsection{Resultados en perspectiva}

Comparado con el pasado, los resultados fueron evidentemente pobres. Los datos preliminares muestran que el crecimiento anual promedio entre 2014 y 2017 fue algo mayor a 1,8 por ciento, muy por debajo del 4,7 promedio registrado en los diez años precedentes. Las estimaciones del crecimiento potencial de la economía también se ajustaron significativamente. Por ejemplo, en 2014 la comisión de expertos que calculaba el crecimiento potencial para el balance estructural estimó que éste llegaría a 4,4 por ciento en 2017. La última estimación de ese grupo para ese mismo año fue 2,6 por ciento.

Pero comparar el desempeño sólo con el pasado es un ejercicio incompleto, porque las condiciones que enfrentó la economía pueden haber sido muy distintas en años diferentes (como en el caso de la nota en una prueba, es importante saber la dificultad de la prueba para evaluar la nota). Tampoco es fácil construir un grupo de control adecuado y que el resultado de ese ejercicio sea reconocido por sectores de opinión diversos.

${ }^{23}$ Algo que habría ayudado a despejar eventuales dudas, al menos parcialmente, habría sido el recurrir al Tribunal Constitucional, en algunos de los casos en que diputados aprobaron mociones o indicaciones que eran inconstitucionales. El costo político fue considerado demasiado alto. No recurrir tuvo efectos en incentivos (por ejemplo, en el presupuesto de 2018 el Congreso aprobó cambios que no eran de iniciativa parlamentaria). 
El crecimiento mundial bajó desde 4,1 por ciento en la década previa a 3,4 por ciento, una disminución no trivial, pero bastante menor que la que registró Chile. El crecimiento de Latinoamérica, por otro lado, sufrió una caída mucho mayor: pasó de 4,1 por ciento en la década anterior a sólo 0,4 por ciento en los últimos cuatro años, lo que deja al resultado en Chile como bastante positivo. Como se ve, el grupo de comparación puede hacer una diferencia enorme. ${ }^{24}$

Para una evaluación que intenta avanzar en objetividad, consideramos acá algunos ejercicios basados en la relación histórica registrada en los últimos años entre Chile y distintos grupos de comparación, usando los datos del reciente World Economic Outlook (WEO) del FMI.

Primero, considerando una regresión lineal entre el crecimiento de Chile y un promedio de países, entre 1998-2013, se proyecta el desempeño esperado de nuestra economía dado el comportamiento del grupo de control en 2014-16 (y hasta 2017). ${ }^{25}$ Esto permite controlar tanto por el nivel de crecimiento promedio como por la sensibilidad de Chile a factores comunes. Los resultados indican que el crecimiento esperado depende del grupo de control y va entre 1,6 y 3,7 por ciento (tabla 1).

Tabla 1. PROYECCIONES DE CRECIMIENTO PARA CHILE CON AGREGADOS Y SINTÉTICOS (\%)

\begin{tabular}{lcc}
\hline & $2014-16$ & $2014-17(p)$ \\
\hline Mundo & 3,7 & 3,6 \\
Emergentes y ED & 3,1 & 2,5 \\
América Latina & 1,6 & 1,7 \\
Sintético 3 paises & 2,7 & 2,7 \\
Sintético 4 paises & 2,7 & 2,7 \\
Efectivo & 1,7 & 1,7 \\
\hline
\end{tabular}

Fuente: Elaboración propia con datos WEO.

${ }^{24}$ Bergoeing $(2017,12)$ hace diversas comparaciones, entre Chile y grupos de países, concluyendo que "Chile se estancó recientemente porque ha hecho las cosas mal...", asignando casi la totalidad de la desaceleración a las reformas. Curiosa conclusión, cuando sus propios cálculos muestran que Chile no tuvo un comportamiento extraño, si se compara con países exportadores de recursos naturales o con América Latina, incluso excluyendo a Brasil.

${ }^{25}$ La muestra de estimación es corta. Sin embargo, tanto el comportamiento cíclico como el crecimiento potencial parecen haber cambiado en Chile postcrisis asiática. 
Si se consideran los países emergentes y en desarrollo, que posiblemente sean el comparador adecuado (frente al mundo completo, dado el peso de los países desarrollados, o a América Latina, dado el peso de Brasil), la proyección es de 2,5 por ciento, lo que se compara con crecimientos efectivos de 1,7 por ciento. Asignando todo el residuo a "causas internas", ellas explicarían entonces del orden de tres cuartos de punto de menor crecimiento. Por cierto, éste es un supuesto extremo, porque no considera, por ejemplo, que la política macroeconómica, monetaria en particular, podría explicar también una parte. O que simplemente hay otros shocks.

Un segundo ejercicio, más interesante, parte por reconocer que los agregados considerados son ad hoc y que no tienen por qué explicar el crecimiento de Chile, sea porque incluyen países irrelevantes o porque ponderan más a los países grandes. Para subsanar esto y construir un mejor comparador, consideramos un indicador sintético que agrega un conjunto de países que mostraron a partir de 1998 una mayor correlación con el crecimiento de Chile. ${ }^{26}$

Los resultados ponen el crecimiento proyectado para Chile en 2014-16 (y 2017) en 2,7 por ciento en el caso de los grupos sintéticos, y en un rango de 2,6 a 3,3 por ciento, con varios en torno a 2,8-2,9 por ciento en el caso del promedio de países (gráfico 17). Con este ejercicio, las "causas internas" podrían explicar en torno a un punto de menor crecimiento.

También es posible analizar cambios en el PIB potencial. Para eso, comparamos el cambio en las del WEO del FMI para cada país en los últimos cinco años, entre 2017 y 2013. Una proyección a cinco años contiene la percepción de potencial, ya que a ese horizonte los factores cíclicos han desaparecido.

Comparado con los países que aparecen en la última página de la revista The Economist (que entrega estadísticas), el cambio de proyec-

${ }^{26}$ El procedimiento es el siguiente: se ordena un conjunto amplio de países (en este caso 60, los más relevantes en el mundo, la región y Asia, además de algunos exportadores de materias primas, que aparecen regularmente en las estadísticas de la revista The Economist) de acuerdo al $\mathrm{R}^{2}$ de la regresión entre el crecimiento de Chile y el del país respectivo en 2008-2013. En el caso de un sintético, se van agregando países adicionales escogiéndolos según maximicen el $\mathrm{R}^{2}$ corregido. En el caso del promedio sintético, simplemente se promedian las proyecciones para el periodo de interés tomando en cuenta $\mathrm{N}$ países en regresiones independientes. 
Gráfico 17. PROYECCIONES DE CRECIMIENTO PARA CHILE CON PROMEDIOS DE PAÍSES SINTÉTICOS (\%)

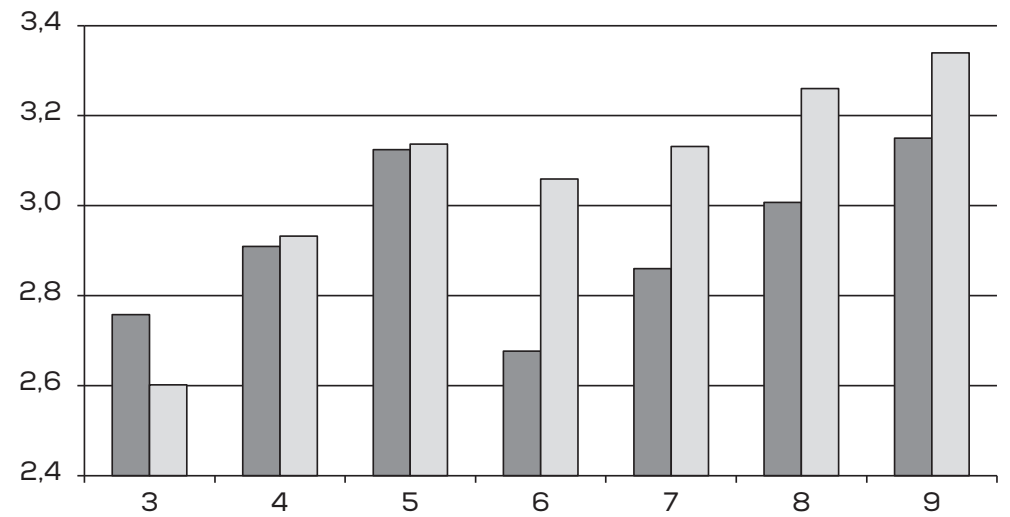

Número de países con mayor correlación con el crecimiento de Chile desde 1998

$$
\square 2014-16 \quad \square 2014-17
$$

Fuente: Elaboración propia con datos WEO.

ciones para Chile se ve muy negativo: disminuye 1,2 puntos porcentuales, desde 4,5 a 3,3 por ciento, mientras el promedio de estos países cae sólo 0,4 por ciento. Más relevante, Chile se ubica en el 11 por ciento inferior de la distribución.

Otra vez, sin embargo, es importante contrastar a Chile con países similares, específicamente en la región y con un grupo de países exportadores de materias primas (gráficos 18 y 19). En comparación con el promedio simple de Sudamérica, Chile tuvo una caída de proyecciones sólo un par de décimas mayor y fue similar al promedio simple de los seis países exportadores de materias primas considerados.

En suma, una parte importante de la desaceleración (y, por lo tanto, de la posterior aceleración) obedece a factores externos. La división dos tercios y un tercio parece coherente con los datos analizados.

Cabe mencionar que el desempleo se mantuvo sorprendentemente bajo considerando la desaceleración. Tanto en datos del Instituto Nacional de Estadísticas (INE) como de la Universidad de Chile, la tasa de desempleo durante este periodo fue menor que sus promedios históricos. Por cierto, la creación de empleo fue menos robusta, con un rol más significativo del autoempleo que en algunos períodos anteriores, pero sigue siendo cierto que el mercado laboral capeó bastante bien este 
Gráfico 18. CAMBIO DE PROYECCIÓN DE CRECIMIENTO A 5 AÑOS 2017 VS 2013 (\%)

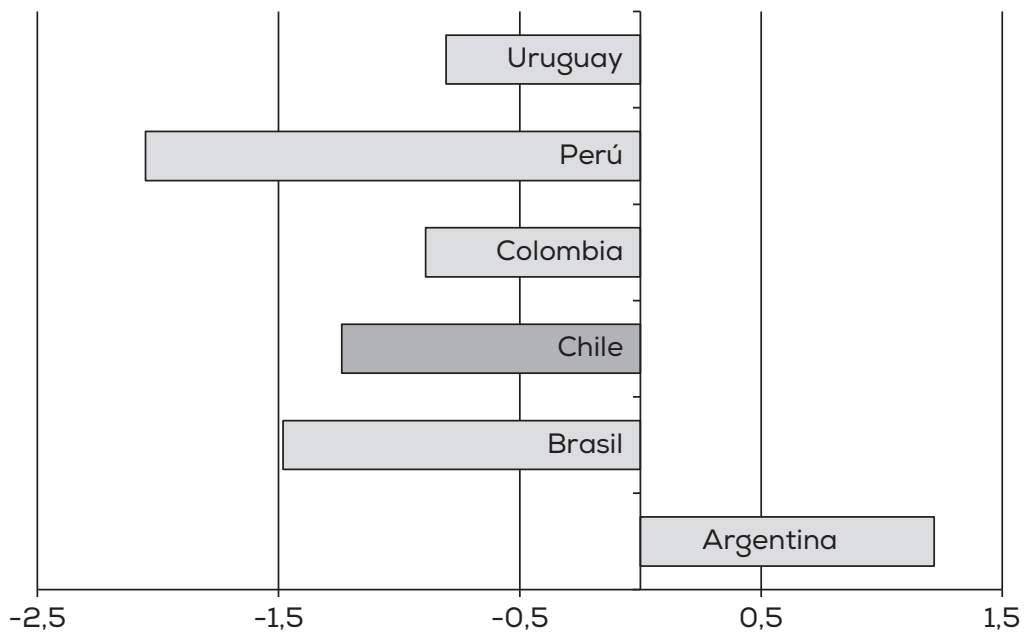

Fuente: Elaboración propia con datos WEO.

Gráfico 19. CAMBIO DE PROYECCIÓN DE CRECIMIENTO A 5 AÑOS 2017 VS 2013 (\%)

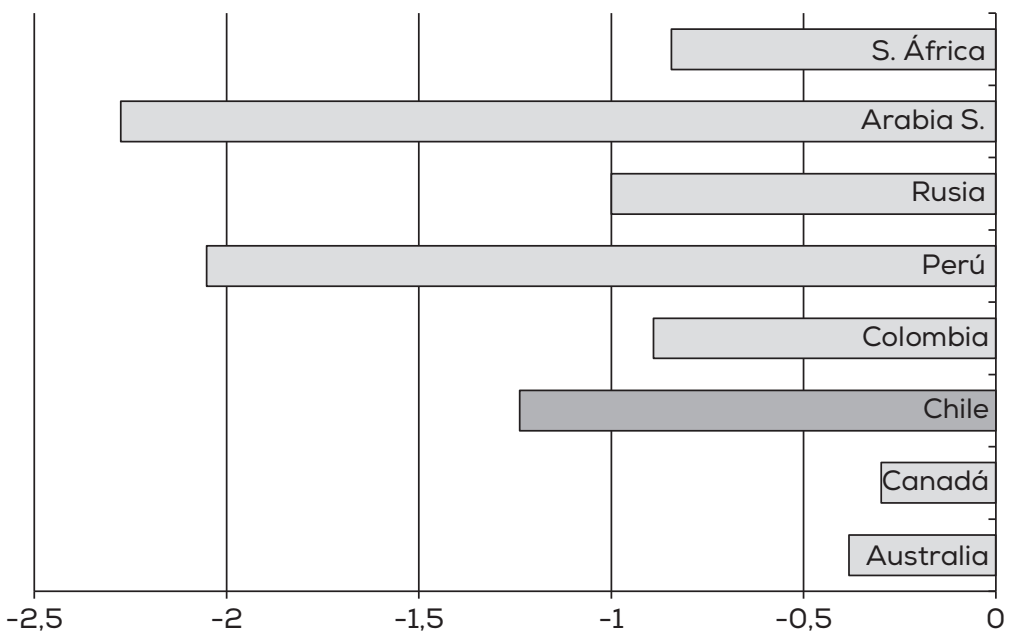

Fuente: Elaboración propia con datos WEO. 
ciclo. Aunque éste fue un fenómeno que también se apreció en otros países de la región, se debe considerar el rol de la contención salarial como un importante factor doméstico.

Estimaciones preparadas en Hacienda y presentadas en la Comisión de Trabajo de la Cámara de Diputados sugerían que si los salarios no se hubieran desacelerado, el desempleo podría haber sido 2 y hasta 3 puntos porcentuales mayor. El convencimiento siempre fue que el reajuste del sector público y el del salario mínimo debían ser moderados por la dimensión fiscal, pero incluso más relevante era su influencia en la dinámica salarial. Era socialmente mejor que los salarios crecieran poco a que muchos perdieran su empleo.

\section{3. ¿Qué priorizar en los próximos trimestres?}

Para comenzar, en la medida en que es correcta la hipótesis de que parte importante de este ciclo obedece al ajuste del sector minero y sus efectos colaterales, es esperable que la recuperación del precio del cobre haga que, primero, se desate un aumento de inversiones, de contratación y, más tarde, de producción. Cuando la inversión en este sector ha disminuido tanto - por ejemplo, las importaciones de maquinaria para el sector resultaron en 2017 en torno a 30 por ciento de lo que fueron en 2012-, el potencial de crecimiento es muy grande.

Esto, sin embargo, también enfrenta riesgos. Uno evidente es que el precio del cobre no se mantenga en el tiempo, aunque expertos estiman que la electromovilidad parece ser una nueva realidad que sostendrá la demanda. Otro es la dificultad que enfrenta la inversión para materializarse. Los permisos requeridos y el poco apoyo a grandes proyectos, especialmente a nivel local, podrían ralentizar esta recuperación. Es necesario modernizar el proceso de otorgamiento de permisos, ambientales y de otro tipo, y generar mayores certezas respecto del respaldo con que podrían contar los proyectos en las comunidades donde se insertan y de parte de los actores relevantes de esas zonas.

Para proseguir con qué priorizar en los próximos trimestres, la infraestructura concesionada puede escalarse bastante. En octubre de 2017 se aprobó la ley que crea la Dirección de Concesiones en el Ministerio de Obras Públicas, una nueva institucionalidad que da más herramientas al Estado y que debería hacer más ágil la ejecución. El 
Fondo de Infraestructura, también puede ayudar al mismo objetivo, especialmente porque tendrá la responsabilidad de buscar nuevos proyectos. Urge actualizar la cartera de proyectos y dejar de depender tanto de las iniciativas privadas. También hay que aprovechar que los fondos de pensiones pueden invertir en activos alternativos, entre ellos, infraestructura. Si desde la industria de pensiones hay dudas e incertidumbre respecto de cómo se tratarán estos activos en una eventual reforma, es importante clarificarlas y eliminarlas.

Asimismo, hay oportunidades para afinar algunas de las reformas recientes, con modificaciones que reduzcan sus eventuales distorsiones o permitan ganar espacios de eficiencia que no se han ocupado. Por ejemplo, en el tema laboral conviene establecer servicios mínimos más robustos y reincorporar los pactos de adaptabilidad, ojalá amplios. En lo tributario, podría simplificarse el sistema a través de desintegrarlo o integrarlo por completo, con las compensaciones necesarias en recaudación, pagadas por los mismos agentes económicos. En educación es necesario tener una evaluación de cada uno de los cambios que se han impulsado, y parece evidente que hay que seguir invirtiendo más recursos en educación preescolar, idealmente conectando este esfuerzo con los que se hacen en términos de cuidado infantil para aumentar la participación laboral femenina.

Además, la experiencia de tener una Comisión de Productividad independiente y, adicionalmente, de que los proyectos de ley deban ser acompañados de un informe de productividad (además del habitual informe financiero) ha sido positiva. Hay que profundizar estos esfuerzos y avanzar en su institucionalización, de manera que el sistema político, tanto en el diseño como en la discusión de políticas públicas, tome más en cuenta los efectos de sus decisiones.

Y, finalmente, parece necesario redoblar esfuerzos para reconstruir consensos básicos. No es suficiente un cambio de gobierno para eliminar riesgos si la polarización se mantiene, y menos aún si se acrecienta. Temas tan básicos como la constitución, los diseños fundantes del sistema de pensiones o del financiamiento universitario no deberían estar permanentemente bajo amenaza. Por cierto, buscar estos acuerdos es una tarea especialmente ardua, pero sin ellos parece difícil que Chile pueda retomar una senda de desarrollo robusto en el tiempo. 


\section{COMENTARIOS FINALES}

Cuando imaginamos hacia dónde debería encaminarse nuestra sociedad y pensamos en la construcción de nuevos consensos sobre aspectos básicos de nuestra institucionalidad, es útil preguntarnos a qué país queremos parecernos cuando seamos desarrollados. Las respuestas varían, pero nos llevan a varios puntos comunes importantes.

Es difícil encontrar respuestas que propongan países que tengan un sistema económico distinto al capitalista, con un mecanismo de protección claro de lo privado. Es difícil encontrar proponentes de modelos que nos lleven a un tamaño del Estado más pequeño que el actual, y menos a uno con una peor distribución del ingreso. En todos los casos, son naciones en que se valoran enormemente la democracia y la libertad. Aunque es imprescindible construir más mínimos comunes, es posible que exista más coincidencia que la que sugiere el debate diario.

En momentos cuando la socialdemocracia en el mundo y en Chile pasa por momentos difíciles, parece necesario invertir más en reflexión. Hay que partir reconociendo una restricción básica: los países no se construyen en cuatro años ni existen atajos para llegar al desarrollo. Urge también un mejor entendimiento del rol de los incentivos económicos y de la importancia de las ganancias en una economía capitalista del siglo XXI. Y así como hay múltiples temas que requieren de políticas públicas, existen límites que imponen las fallas del Estado para la acción de un gobierno. Un exceso de confianza en la acción estatal puede ser tan problemático como el tema mismo que se quiere atacar.

Por último, hay que considerar que, si bien existen experiencias exitosas de alto crecimiento (Chile es una) y algo sabemos de cómo impulsarlo, prácticamente no existen experiencias exitosas de mejoras rápidas y persistentes en la distribución del ingreso (excepto en revoluciones, con los obvios efectos colaterales). Es perfectamente válido tener como modelo a los países escandinavos, pero no podemos olvidar que éstos han tenido una buena distribución del ingreso por un tiempo prolongado. Las estructuras de Europa continental también se han asentado por largo tiempo y están cruzadas por los efectos de las guerras mundiales. Posiblemente, podemos aprender bastante más de la experiencia de países más nuevos, como Australia, Nueva Zelandia y Canadá, todos con una base amplia de recursos naturales, comunidades indígenas importantes y hoy altamente desarrollados. 


\section{REFERENCIAS}

Ahumada, B., M. P. Lagos \& D. Sugg. 2016. "Sobregasto operacional y deuda del Sistema Nacional de Servicios de Salud". Serie Estudios de Finanzas Públicas, Dipres. Octubre.

Bergoeing, R. 2017. "Por qué cayó el crecimiento en Chile". Puntos de Referencia 470, Centro de Estudios Públicos.

Calderón, C., A. Chong \& R. Valdés. 2005. "Labor Market Regulations and Income Inequality: Evidence for a Panel of Countries". En Labor Markets and Institutions, editado por J. Restrepo \& A. Tokman. Santiago: Central Bank of Chile.

Calderón, C., A. Chong \& G. León. 2007. "Institutional Enforcement, LaborMarket Rigidities, and Economic Performance". Emerging Markets Review 8 (1): 38-49.

Cerda, R., A. Silva \& T. Valente. 2016. "Índice de incertidumbre económica: medición e impacto". Mimeo, Clapes UC.

Corbo, V., R. Caballero, M. Marcel, F. Rosende, K. Schmidt-Hebbel, R. Vergara \& J. Vial. 2011. Propuestas para perfeccionar la regla fiscal. Comité Asesor para el Diseño de una Política Fiscal de Segunda Generación para Chile. Santiago: Dipres.

Dipres. ¿2017? "Informe de Finanzas Públicas. Proyecto de Ley de Presupuestos del Sector Público para el año 2018”.

Engel, E., C. Neilson \& R. Valdés. 2010. "Chile's Fiscal Rule as Social Insurance”. En Fiscal Policy and Macroeconomic Performance, editado por Luis Felipe Céspedes \& Jordi Galí. Santiago: Central Bank of Chile.

Epple, D., R. Romano \& R. Zimmer. 2015. "Charter Schools: A Survey of Research on Their Characteristics and Effectiveness". NBER Working Paper 21256. Septiembre.

Galleguillos, P., T. Hernández, F. Sepúlveda \& R. Valdés. 2016. "Reforma a la educación superior. Financiamiento actual y proyecciones". Serie Estudios de Finanzas Públicas, Dipres. Octubre.

Rubio, E. \& R. Vergara. 2017. "Carga y estructura tributaria en Chile. Comparación con países OCDE”. Puntos de Referencia 470, Centro de Estudios Públicos. EP 